\title{
15. PACKER EXPERIMENTS ALONG THE DÉCOLLEMENT OF THE BARBADOS ACCRETIONARY COMPLEX: MEASUREMENTS OF IN SITU PERMEABILITY ${ }^{1}$
}

\author{
Andrew T. Fisher ${ }^{2}$ and Gretchen Zwart ${ }^{2}$
}

\begin{abstract}
The first in situ measurements of permeability and fluid pore pressure along the décollement zone (a low-angle detachment fault) between the North American and Caribbean Plates were completed during Ocean Drilling Program Leg 156. Measurements of properties within the fault zone were attempted at two sites using a drill string packer. Interpretation of the packer data was complicated by variations in the baseline formation fluid pressure during the tests, as well as temporal and spatial variations in formation properties. These measurements may be interpreted to reflect a consistent relationship between bulk permeability and vertical effective stress and between bulk permeability and the modified pore-pressure ratio. Measured bulk permeabilities from the most reliable tests varied from $6 \times 10^{-16} \mathrm{~m}^{2}$ to $1 \times 10^{-13} \mathrm{~m}^{2}$, whereas vertical effective stress varied from 1.7 to $0.1 \mathrm{MPa}$ and the modified pore-pressure ratio varied from 0.45 to 0.95 . These bulk permeability values and trends are consistent with a variety of independent, less direct estimates. These trends may help to explain the transient nature of prism dewatering and fluid flow along faults in this setting.
\end{abstract}

\section{INTRODUCTION}

It has long been a goal of ocean drilling to measure the hydrologic properties along an active plate boundary fault. Fluids are known to play an important role in the tectonic evolution of sediments in such settings at both macro and micro scales. Fluid having pressures in excess of hydrostatic may allow the weak, semilithified sediments of a shallow accretionary system to glide aseismically over an underthrust plate along a low-angle detachment surface (Hubbert and Rubey, 1959; von Huene and Lee, 1983). Highly pressured fluids are thought to contribute to the core/scale deformation of sediments from such margins (Brown and Behrmann, 1990; Brown et al., 1994). Overpressured fluids may also be responsible for the presence of long, mechanically "weak" faults along crustal transform boundaries (Bylerlee, 1990; Kerr, 1992; Rice, 1992).

Previous attempts to measure in situ permeability and fluid pressure within an active plate boundary fault have generally been unsuccessful (Barbados accretionary complex: Mascle, Moore, et al., 1988; Nankai accretionary complex: Taira, Hill, Firth, et al., 1991), although the first such measurements were completed recently within a shallow fault along the Cascadia accretionary margin (Screaton et al., 1995). In this report, we present results from in situ testing during Leg 156 at Sites 948 and 949. Whereas the quantitative results of these tests apply only to the Barbados décollement (and only at two specific locations), they may provide insight as to relations between fluid pressures and hydrologic properties in other settings.

\section{GEOLOGIC SETTING}

Ocean Drilling Program (ODP) Leg 156 investigated the subseafloor hydrogeology of the plate boundary between the North American and Caribbean Plates, occupying three sites along an eastwest transect established during two previous drilling expeditions

${ }^{1}$ Shipley, T.H., Ogawa, Y., Blum, P., and Bahr, J.M. (Eds.), 1997. Proc. ODP, Sci. Results, 156: College Station, TX (Ocean Drilling Program).

${ }^{2}$ Earth Sciences Department, University of California, Santa Cruz, Santa Cruz, CA 95064, U.S.A. afisher@earthsci.ucsc.edu
(Moore et al., 1982; Moore et al., 1988). In this region, the décollement zone separates Miocene and younger accreted claystone and ash from relatively undeformed Oligocene claystone, siltstone, and chalk (Moore et al., 1988; Shipley et al., 1994).

Site 948 was located $4.5 \mathrm{~km}$ arcward of the deformation front of the Barbados accretionary complex, within $200 \mathrm{~m}$ of ODP Leg 110 Site 671 (Fig. 1). At this location the accretionary complex above the décollement is about $500 \mathrm{~m}$ thick, and the underthrust sedimentary sequence (overlying volcanic basement) is about $400 \mathrm{~m}$ thick. Site 948 was located in an area where the décollement zone is displayed as a positive (normal) polarity seismic reflector (Shipley et al., 1994).

Site 949 was located $2 \mathrm{~km}$ arcward of the deformation front, approximately $2 \mathrm{~km}$ northeast of Site 948 . At Site 949 , the accretionary complex above the décollement is about $400 \mathrm{~m}$ thick. Site 949 was located where the décollement displays a negative (reversed) seismic polarity, although the amplitude of the reflector is not as great at Site 949 as at Site 947. In addition, the décollement reflector bifurcates below Site 949, perhaps indicating the presence of a fault splay or other complexity in the large-scale deformation at this site (Moore et al., 1995).

\section{OPERATIONAL OVERVIEW}

Leg 156 packer tests are described in detail in Shipley, Ogawa, Blum, et al. (1994), and are summarized below. Packer testing during Leg 156 required casing to and screening through the décollement. This was made possible through deployment of several technologies new to scientific ocean drilling, including simultaneous underreaming and casing emplacement, deployment of wire-wrapped perforated casing, and establishment of reentry holes with triple-hanger casing.

The borehole configurations at Sites 948 and 949 are summarized in Figure 2 and Table 1. An inner casing extends from the seafloor to the bottom of each hole, including screened and perforated sections that permit communication of borehole fluids with the surrounding formation. An outer casing extends from the seafloor to close to the top of the screened casing in each hole. The annulus between these two casings is sealed near the seafloor. The bottom of the casing in Hole 949C was sealed with a mechanical plug, whereas the bottom of the casing in Hole 948D was not sealed. 


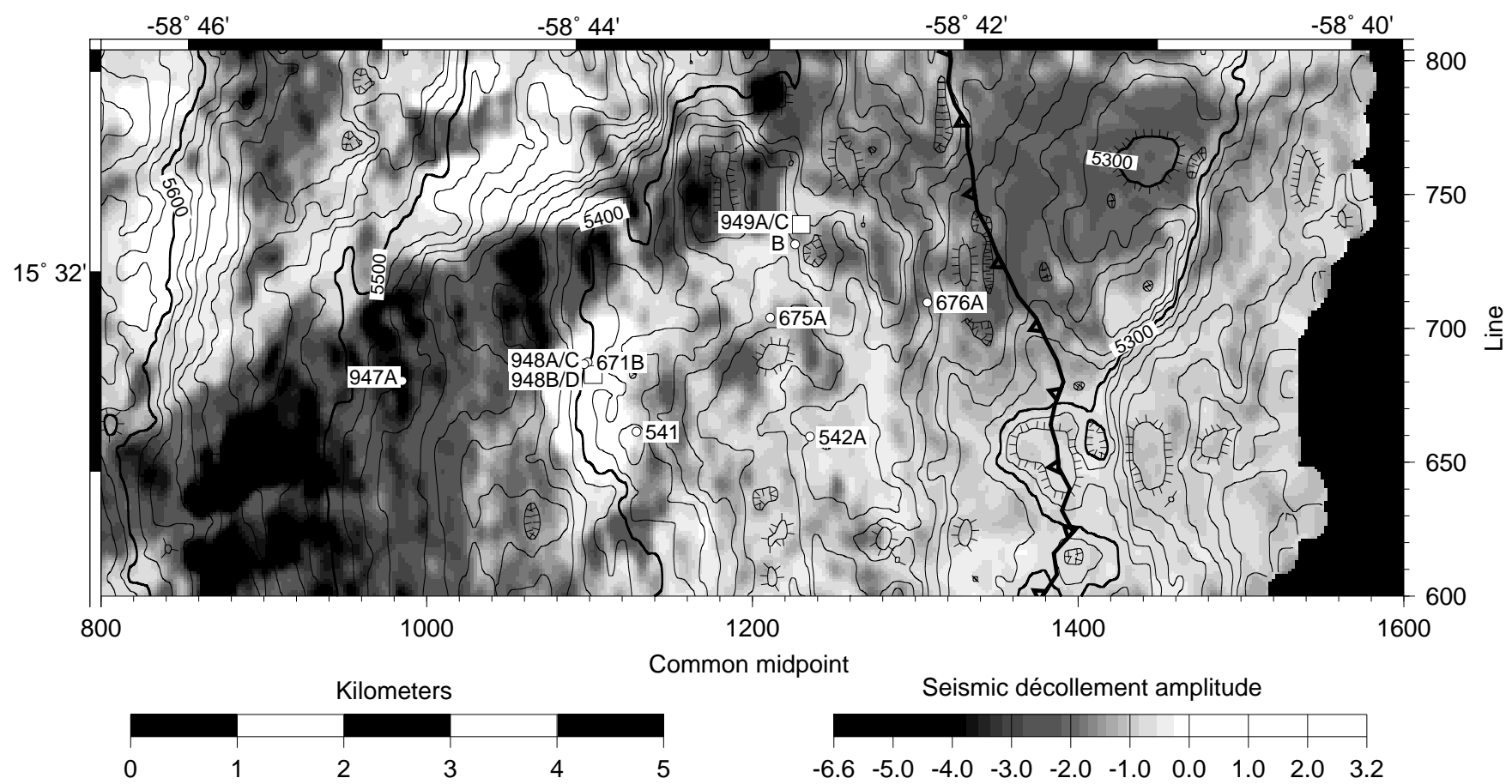

Figure 1. Seismic amplitude superimposed on water depth contours (in meters) along the décollement near the toe of the Barbados accretionary complex (Shipley et al., 1994). DSDP and ODP sites are shown with small circles, and the sites at which packer experiments were conducted are indicated with large squares (modified from Shipboard Scientific Party, 1995b).

\section{Packer Testing}

Permeability was measured in Holes 948D and 949C using a resettable drillstring packer manufactured by TAM International and described by Becker (1990a). The packer incorporates a rubber element that is inflated to isolate a section of the hole. The packer was run with a single inflation element during all Leg 156 operations. In this configuration, the packer isolates and tests the portion of the formation between the bottom of the element and the bottom of the hole. One day before the packer experiments in each hole, the plumbing system (from the pumps, through the top drive, to the rig floor) was tested at high pressure for leaks. The system was pressurized to 14 $\mathrm{MPa}$ and held closed. Minor leakage was eliminated through greasing and tightening of several valves, making the system pressure tight for all subsequent operations.

The packer is installed as part of the drill string, a previously prepared hole is reentered, and the pipe is lowered into position to place the packer element at the desired location. Drilling and coring are not possible when the packer is installed in the drill string, as the packer element is relatively fragile and must be kept in tension until it is locked into its testing position. The packer was inflated in casing during all Leg 156 operations. We know that the annulus between the two casing strings was sealed in both holes, because once the packer element was inflated, but before packer testing began, fluid pressures well in excess of hydrostatic were measured and maintained within the isolated intervals.

The packer is actuated using a device that is dropped down the drill pipe into the packer. This device allows drilling fluid (seawater) to be pumped through inflation ports and into the rubber packer element. Once the element is inflated, friction holds the packer against the side of the casing, and the heave compensator begins to "stroke" in response to ship's heave. After the packer element has been shown to be holding against the side of the borehole for at least several minutes, air is let out of the heave compensator to place weight down on the top of the packer. This weight then shifts a control sleeve at the top of the packer, closing the communication path into the packer element and locking the packer in its inflated position. The motion of the control sleeve also opens a passage for fluid to pass through the packer and into the isolated formation.

Setting the packer and keeping the packer inflated once it was set proved difficult during Leg 156 because of slick mud on the wall of the casing, variable sea conditions, and fluid pressures in excess of hydrostatic within the isolated zone. When the packer is set, the driller must balance the force down on the packer (through adjustment of the heave compensator) against the upward force on the packer from below (due to fluid pressure in the isolated zone) and the holding capacity of the element (a function of inflation pressure and the coefficient of friction between the packer element and the casing). A delicate balance must be maintained to keep the packer in an appropriate position during testing.

The device that redirects fluid flow into the packer element also carries pressure gauges to monitor downhole pressures in the test interval. During Leg 156, electronic "ERPG-300" pressure gauges made by Geophysical Research Corporation recorded pressure values at 10.8-s intervals. These downhole pressures are the primary data from which properties are calculated. Unfortunately, these data are not available until the gauge is retrieved upon completion of each set of tests. However, the entire drill string, as well as the isolated zone, was pressurized during testing, and pressure transducers at the surface also were used to provide a real-time indication of downhole events. Pumping rates and total volumes pumped were also measured and recorded at the rig floor during testing. Rig floor gauges were not as accurate as the downhole instruments, nor were they calibrated with the same precision, leading to some ambiguity as to what was happening downhole during the tests.

Once the packer was inflated, two kinds of experiments were used to determine the permeability of the isolated interval: pressure pulse or "slug" tests and constant rate flow tests. The methods used were 
similar to those described by Anderson and Zoback (1982), Hickman et al. (1984), Anderson et al. (1985), and Becker (1989, 1990b, 1991) in conducting packer experiments in Holes 395A, 504B, and 735B during the Deep Sea Drilling Project (DSDP) and ODP. Flow tests generally disturb the pressure field in the formation around the hole much more than pulse tests and were therefore conducted after the slug tests. In addition, because the formation around the screened holes was found to contain fluid at pressures greater than hydrostatic, pulse and flow tests were conducted first in both holes by allowing fluid to flow out of the holes rather than by pumping fluid into the holes. This approach had never been attempted during earlier scientific ocean drilling packer experiments, and gave mixed results during Leg 156.

The downhole and surface pressure gauges used during Leg 156 all measure absolute pressures. Although these gauges recorded similar changes in pressure during all operations, the records are offset from each other by the pressure generated under a hydrostatic water column. The magnitude of this offset depends on the depth of the downhole gauge. In the following discussion of operations, many of the pressures described are those observed at the surface. The pressures used in quantitative analysis of test results are those recorded by the electronic downhole gauges.

\section{Hole 948D}

The packer was set twice in Hole 948D. Pressure records obtained from downhole electronic gauges are shown in Figure 3. The attempted vertical seismic profile experiment immediately prior to packer work in Hole 948D revealed that there had been an obstruction in the casing about $120 \mathrm{~m}$ above the screened zone. The hole had apparently filled in with sediments that had extruded up the casing from below, as the bottom of the casing had not been plugged. The drill string was carefully lowered to bottom while circulating seawater to clear the fill in the hole. Circulation continued for $1 \mathrm{hr}$ with the drill string at the bottom of the hole to be sure that the hole was clear. A plume of muddy water flowed freely from the reentry cone throughout hole cleanup. This flow was clearly visible on the seafloor television picture, as the camera remained deployed throughout packer operations and proved to be useful for evaluating the effectiveness of the packer seal during subsequent operations.

The drill string was then raised, placing the packer at a depth of $472 \mathrm{~m}$ below seafloor (mbsf) in the middle of the first joint of casing above the screened zone (Fig. 2A). The pressure gauge was dropped down the pipe and into the test interval. The gauge landed and hydrostatic pressure was monitored for $30 \mathrm{~min}$. During this time, some drag was felt on the drill string, indicating that the packer was rubbing up against the casing, either because of spontaneous inflation or because of mud coating the inside of the casing, creating a partial seal around the packer.

We inflated the packer element and sealed in pressure at the rig floor. Pressure held for $10 \mathrm{~min}$ with no additional pumping, and the plume of effluent from the cone was reduced, indicating that a hydraulic, as well as a mechanical, seal had been established. The driller then shifted the packer control sleeve by placing additional weight on the packer, and locked the inflated packer element. Normally the control sleeve shifts quickly, opening a passage from the drill ship into the isolated zone, and releasing the inflation pressure remaining in the pipe. The packer behaved differently during this first set. Rather than quickly losing pressure at the rig floor, the drill string lost pressure slowly over the next $8 \mathrm{~min}$. During this time, we noted that the plume from the cone started again and that the packer began to slip down the casing wall.

Pressure in the drill string then began to climb slowly and the packer held position, even with the application of an additional weight. The plume from the cone stopped flowing. We suspect that this short-lived plume was caused by the venting of fluid through re- lief ports above the element when it is set. These open ports apparently also allowed a limited hydraulic connection between the test interval and the annulus between the drill string and casing before the element was set. The slow packer element inflation sequence may have resulted from mud partially fouling these ports and the packer element, as described later. The presence of slick mud on the casing wall also may have reduced the element's holding ability.

We waited 30 min to record pressure in the isolated zone and then began a series of withdrawal pulse and flow tests. We conducted two pulse tests (Tests 1 and 2) by rapidly opening and closing the valve at the cement pump, exposing the isolated zone to hydrostatic pressure. Following each pulse we allowed 20-30 min for recovery. We then opened the valve at the cement pump and allowed the formation to flow back continuously while we measured the flow rate (Test 3). We intended to conduct this flow back test for 20-30 min, and then conduct an additional flow back test at a higher flow rate. After 10 min of flow at $0.45 \mathrm{~L} / \mathrm{s}$, we found the packer to be slipping down the hole. This appears to have occurred, in part, because the loss of pressure in the isolated zone resulted in a loss of upward (piston) force below the packer.

After allowing an additional $30 \mathrm{~min}$ for pressure recovery (Test 4), we attempted our first positive pulse test by quickly pumping into the formation, then shutting in (Test 5). Pressure rose immediately about $400 \mathrm{kPa}$ in response to the pumping, but after a small initial decay, remained elevated and constant for the next hour (Fig. 3A). We elected to retrieve and examine the pressure gauge to evaluate the operating condition of the packer. Deflation took over $1 \mathrm{hr}$, perhaps because of mud packed in above or in the packer element. The pressure data recovered from the downhole gauge provided a complete record of all operations and indicated that the packer was operating properly. We now believe that the solid retention of pressure during the first positive slug test (Test 5) in Hole 948D was caused by clogging of the screen during the withdrawal flow test.

After seawater was circulated to clear the screen, the packer was raised into position, and the downhole gauges were deployed for a second time. After the gauges landed, pressure was monitored passively for $30 \mathrm{~min}$. Then we inflated the element and sealed the pressure at the rig floor. The packer held full pressure for $10 \mathrm{~min}$, so we increased pressure in the element, put weight down on the packer, and locked the inflated packer element (Test 6). This time, surface pressure bled off immediately, as is more typical behavior for packer setting operations, and the packer supported weight without slipping. After another 30-min equilibration period, we conducted three positive pulse tests at successively greater pressures, allowing 15-20 min of recovery after each test (Tests 7-9). We then conducted three injection tests at 2.0,3.9, and $6.3 \mathrm{~L} / \mathrm{s}$, pumping steadily for $20 \mathrm{~min}$ and then shutting in for $20 \mathrm{~min}$ (Tests 10-15).

At the end of these tests, we deflated the packer and recovered the pressure gauge (Fig. 3B). When the packer was recovered, it was found to be packed with sandy, silty clay. For sediment to get into the packer it must be pumped through $1 / 4$ in inflation ports. It is not clear from the operational or pressure records when sediment fouled the packer, but it may have been before the first set of tests, as this could explain the unusual setting behavior.

\section{Hole 949C}

Packer tests in Hole 949C followed emplacement of a mechanical plug intended to prevent flow of sediment up from the bottom of the open casing. Such flow complicated operations in Hole 948D. The plug appears to have been effective, as no sediment was observed exiting the cone when it was located with the TV camera immediately before reentry with the packer.

Following reentry, the packer was lowered to $392 \mathrm{mbsf}$, in the middle of the first joint of casing above the screened zone (Fig. 2B). The pressure gauges were pumped down the drill string, and pressure 
was monitored for $30 \mathrm{~min}$ (Fig. 3C). We inflated the packer element and sealed the system at the rig floor. Pressure held for $10 \mathrm{~min}$ with minor additional pumping. The inflation pressure was increased, weight was set down on the packer, and the inflatable packer element was locked into position, opening communication to the isolated interval.

The isolated zone remained sealed to monitor the pressure decay following setting of the element (Test 1). After waiting $30 \mathrm{~min}$, we began a series of withdrawal pulse and flow tests, exposing the isolated formation to hydrostatic pressure and monitoring pressure recovery. We conducted two negative pulse tests by rapidly opening and closing of the valve at the cement pump, exposing the isolated zone to hydrostatic pressure (Tests 2 and 3). Following each pulse, we allowed $30 \mathrm{~min}$ for pressure recovery. We then opened the valve at the cement pump and allowed fluid to flow out of the formation while we measured the flow rate at the surface (Test 4). Unfortunately, the formation produced little water, and instead the rig floor stand pipe (the highest point in the plumbing system connecting the cement pump to the drillstring) emptied completely, allowing air to enter the pipe. We waited for $60 \mathrm{~min}$, but pressure did not recover, so the pipe had to be manually refilled with water. We then attempted three positive slug tests by pumping briefly into the formation, then monitoring the pressure response (Tests 5, 6, and 7). Finally, we attempted an injection test by pumping at $2.0 \mathrm{~L} / \mathrm{s}$ for $20 \mathrm{~min}$ (Test 8 ). By the end of the injection recovery test, the weight on the packer had risen, indicating that the packer was being pushed up the hole from below. We allowed 30 min for pressure recovery (Test 10), then deflated the packer and retrieved the pressure gauge.

While we were preparing the pressure gauge for a second series of tests, we checked the depth of the hole and found it to contain 10-12 $\mathrm{m}$ of fill at the bottom (below the bottom of the screen). The hole was cleared and flushed with seawater for $30 \mathrm{~min}$. We conducted the second set of tests in Hole 949C with the packer at 387 mbsf, because this placed the packer element at the connection between two pieces of casing. We hoped that the irregular shape of the casing at this point would help to hold the packer in position during testing.

The pressure gauges were pumped down the drill string and into the packer. Ship heave had increased significantly and the packer was inadvertently set twice before the element could be locked fully inflated. The pipe was shut in for $30 \mathrm{~min}$ (Test 10), followed by a second injection pulse test (Test 11). We then conducted an injection flow test at $3.2 \mathrm{~L} / \mathrm{s}$ (Test 12), but after about 20 min the packer and drill string began to rise up the hole. Pumping was stopped and the drill string was held closed for 60 min (Test 13). We then vented the pressure and pulled up on the packer, deflating the element, and retrieved the pressure gauges.

\section{INTERPRETATION OF PACKER TEST RESULTS Interpretation of Relative Pressures}

Before quantitatively interpreting the packer test results, we define several terms and explain how results from different depths and pressure regimes can be compared. Hydrostatic pressure at any depth is the pressure exerted by the overlying water column,

$$
\mathrm{P}_{\mathrm{H}}(\mathrm{z})=\int_{0}^{\mathrm{z}} \rho_{\mathrm{w}}\left(\mathrm{z}^{\prime}\right) \mathrm{gdz^{ \prime }} \approx \sum_{\mathrm{i}=1}^{\mathrm{n}} \rho_{\mathrm{w}}\left(\Delta \mathrm{z}_{\mathrm{i}}\right) \mathrm{g} \Delta \mathrm{z}_{\mathrm{i}},
$$

where $\rho_{w}$ is water density, $g$ is gravitational acceleration, and $z^{\prime}$ is a dummy variable. Water density is a function of depth (pressure), temperature, and salinity. The fluids collected in ODP Holes 948D and 949C were close enough in salinity to seawater to allow salinity dependence to be ignored. Temperature differences are important only in the upper water column and deep below the seafloor, as tem-

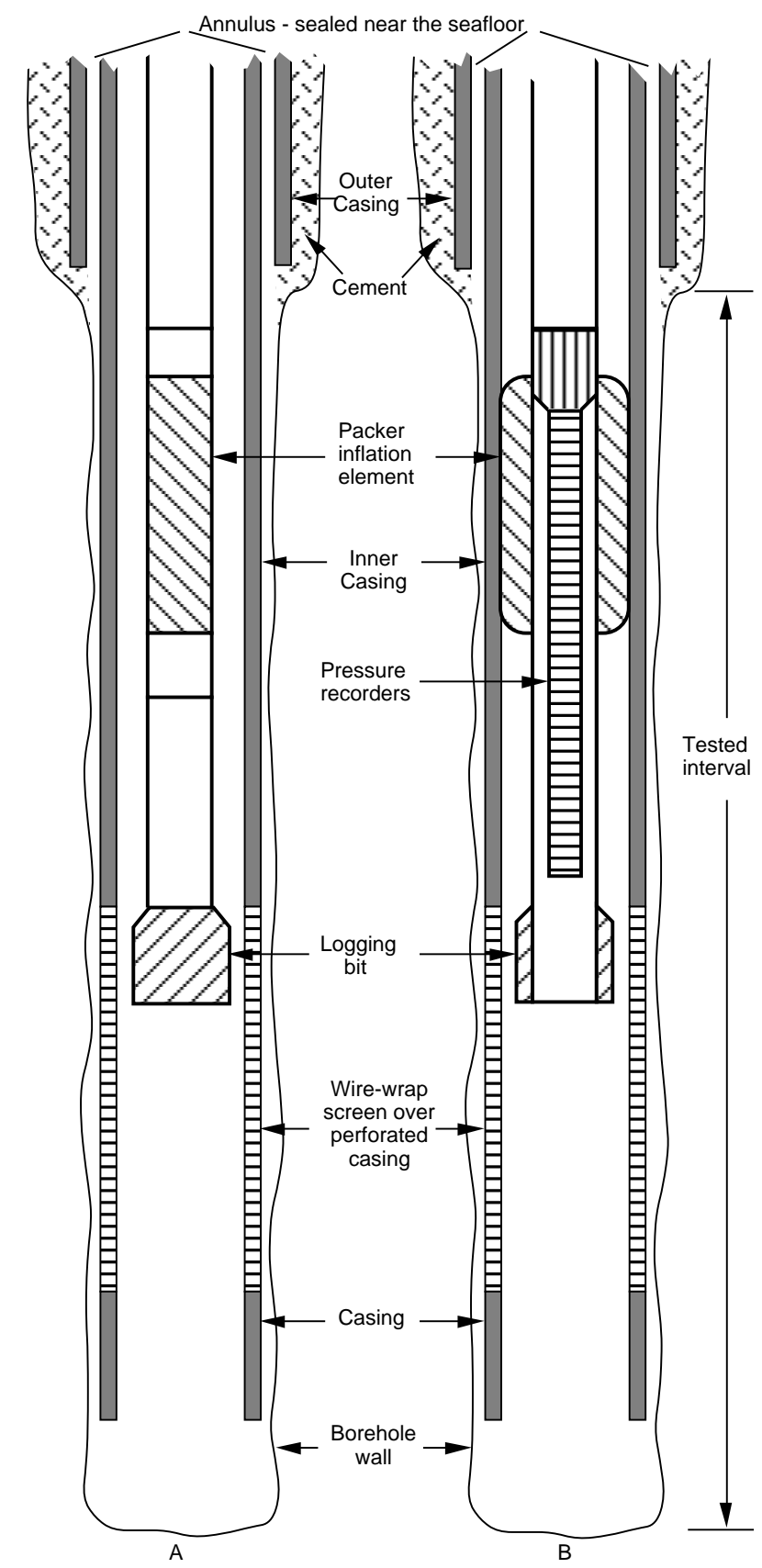

Figure 2. Configuration of packer experiments conducted during Leg 156. A. Packer is lowered into case hole with uninflated element. B. Device holding pressure gauges is dropped down drill string, and packer element is inflated, isolating interval outside casing from the base of the cement to the bottom of the hole. Installation of a plug at the base of the casing may help reduce sediment flow up the pipe, but it does not change the dimensions of the isolated zone. C. Configuration of packer experiment in Hole 948D. D. Configuration of packer experiment in Hole 949C. In each hole, solid casing was run from the seafloor to the depth immediately above the zone of interest. After drilling out the hole below the first casing, another casing string containing a wire-wrapped, perforated interval was then run from the seafloor across the zone of interest. The annulus between these two casing strings was sealed just below the cone. Note the absence of a plug at the bottom of Hole 948D. The location of the structural décollement was defined based on observations of cores recovered from these holes and from adjacent exploratory holes (Shipboard Scientific Party, 1995a, 1995b). 

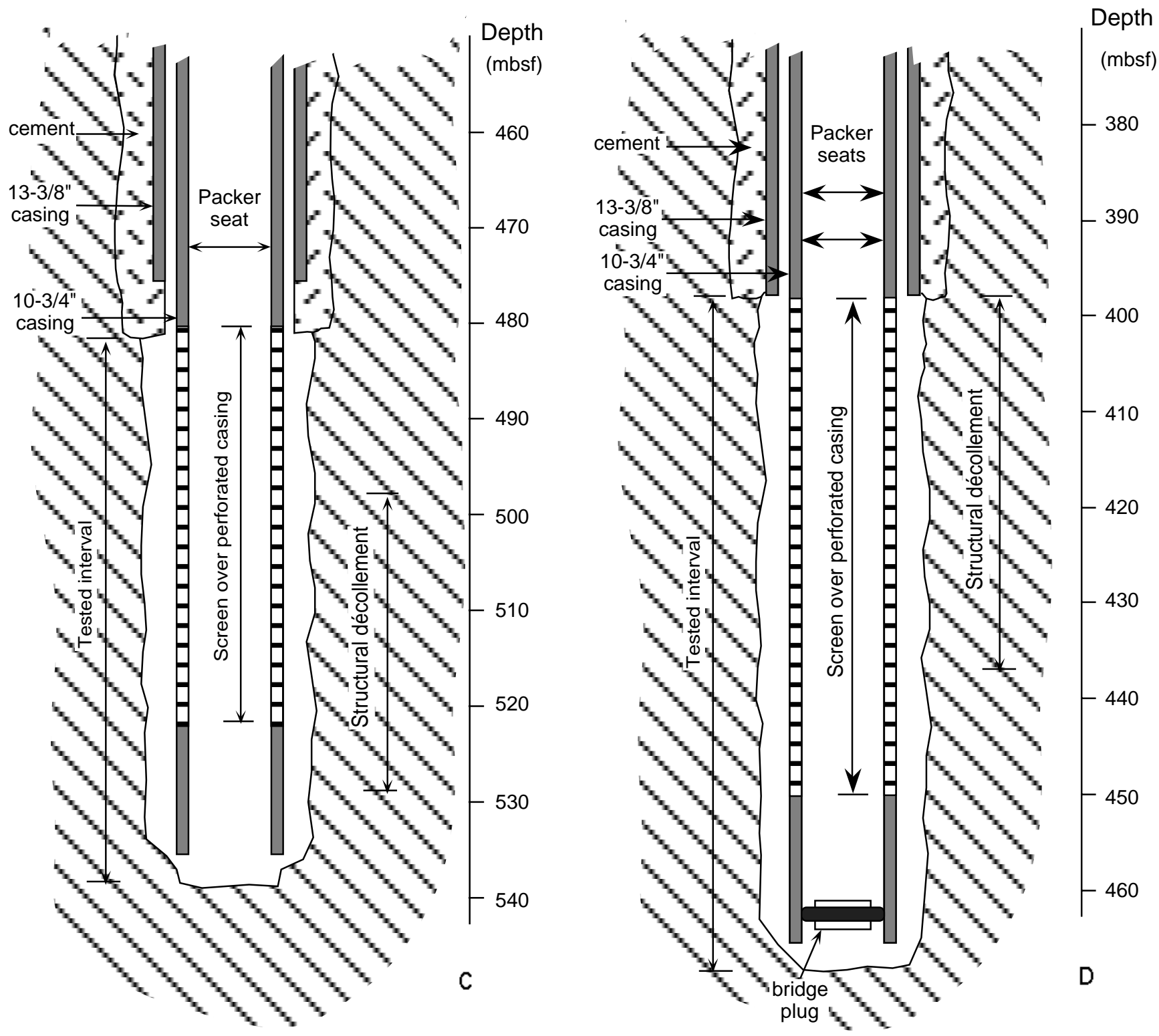

Figure 2 (continued).

Table 1. Summary of hole configuration information and fluid pressures during packer testing.

\begin{tabular}{|c|c|c|c|c|c|c|c|}
\hline \multirow[b]{2}{*}{ Hole } & \multirow[b]{2}{*}{$\begin{array}{l}\text { Packer seat } \\
\quad(\mathrm{mbsf})\end{array}$} & \multirow[b]{2}{*}{$\begin{array}{l}\text { Depth to top of } \\
\text { test interval } \\
\text { (mbsf) }\end{array}$} & \multirow[b]{2}{*}{$\begin{array}{l}\text { Depth to bottom of } \\
\text { test interval * } \\
\quad(\mathrm{mbsf})\end{array}$} & \multicolumn{2}{|c|}{ Hydrostatic pressure } & \multicolumn{2}{|c|}{ Lithostatic pressure } \\
\hline & & & & $\begin{array}{c}\text { At top of } \\
\text { test interval* } \\
(\mathrm{MPa})\end{array}$ & $\begin{array}{l}\text { At bottom of } \\
\text { test interval* } \\
\text { (MPa) }\end{array}$ & $\begin{array}{l}\text { At top of } \\
\text { test interval* } \\
\text { (MPa) }\end{array}$ & $\begin{array}{l}\text { At bottom of } \\
\text { test interval* } \\
\text { (MPa) }\end{array}$ \\
\hline 948D & 474 & 481 & 538 & 55.314 & 55.896 & 59.014 & 60.056 \\
\hline $949 \mathrm{C}$ & $392,388 \dagger$ & 398 & 468 & 55.015 & 55.725 & 57.805 & 59.045 \\
\hline
\end{tabular}

Notes: $*$ hydrostatic pressures at depths greater than the pressure gauge are based on measured hydrostatic pressure and the calculated additional pressure associated with greater depth. Lithostatic pressures are based on integrated bulk density curves derived from logging-while-drilling and core data. $\dagger=$ packer set at different depths during first and second gauge deployment.

peratures otherwise are relatively constant. Hydrostatic pressures were calculated at the depths of the holes occupied during packer testing through use of a modified fluid-properties program for pure water (Haar et al., 1984; Fisher et al., 1994), with an offset to account for the salinity of seawater (about $25 \mathrm{~kg} / \mathrm{m}^{3}$; Stommel, 1965). These calculations yield values that are consistent with downhole hydrostatic pressure measurements.
Lithostatic pressure at any depth below the seafloor is the pressure exerted by the overlying water and sediment columns,

$$
\mathrm{P}_{\mathrm{L}}(\mathrm{z})=\mathrm{P}_{\mathrm{Hsf}}+\int_{\mathrm{z}_{\mathrm{sf}}}^{\mathrm{z}>\mathrm{z}_{\mathrm{sf}}} \rho_{\mathrm{b}}\left(\mathrm{z}^{\prime}\right) \mathrm{g} \mathrm{dz} \approx \mathrm{P}_{\mathrm{Hsf}}+\sum_{\mathrm{i}=1}^{\mathrm{n}} \rho_{\mathrm{b}}\left(\Delta \mathrm{z}_{\mathrm{i}}\right) \mathrm{g} \Delta \mathrm{z}_{\mathrm{i}},(2)
$$



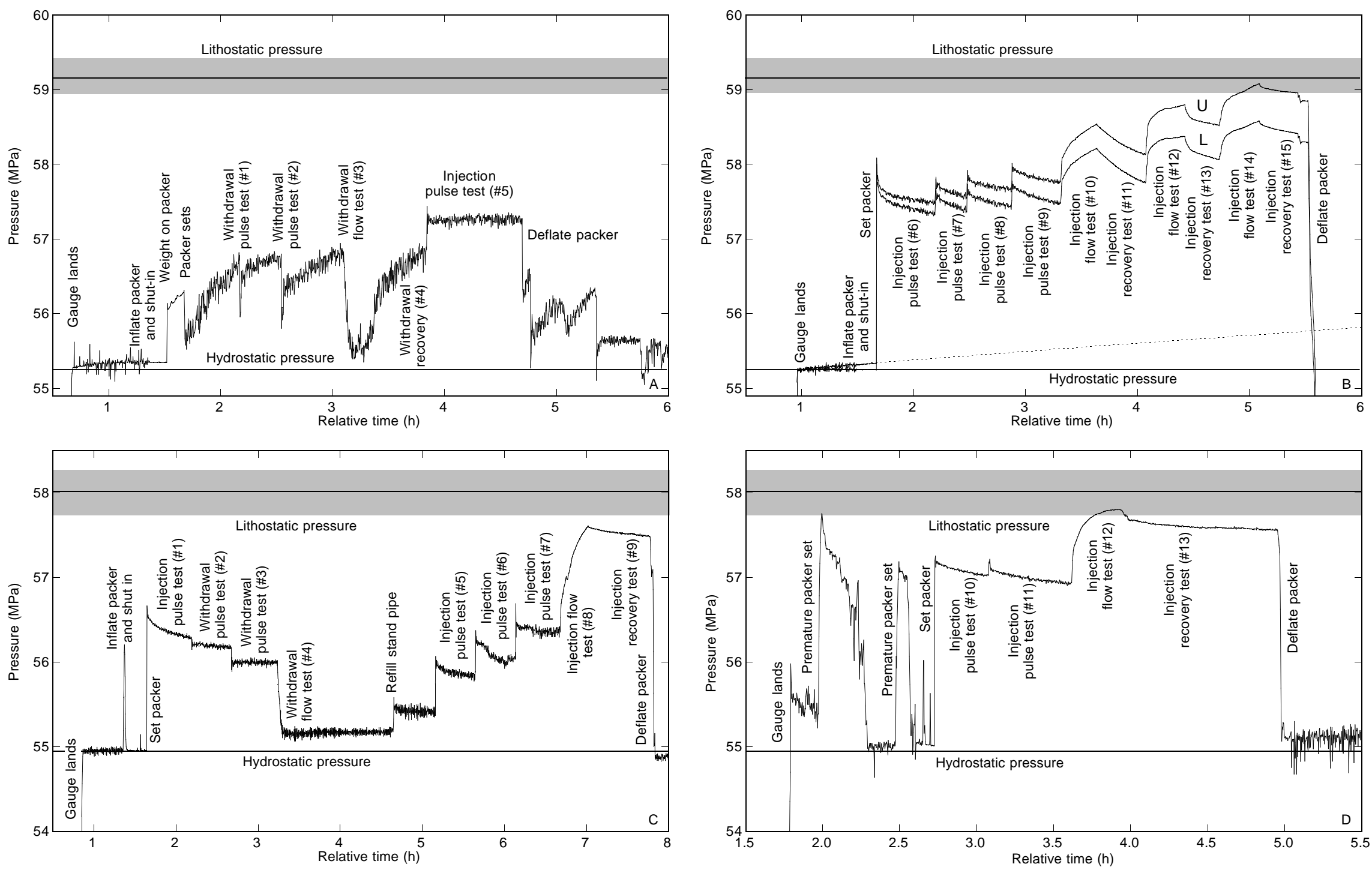

Figure 3. Annotated pressure vs. relative time (since starting the electronic gauge) for all packer tests in Holes 948D and 949C, illustrating measured pressures and equivalent hydrostatic and lithostatic pressures over the test intervals. Hydrologic tests are numbered sequentially for each hole. Not all tests yielded quantitative results, as described in the text and summarized in Tables 3 and 4 . Hydrostatic pressures are shown by the lower horizontal line in each figure, while a range of lithostatic pressures is indicated by the striped intervals near the top of each figure. The horizontal line within the stripe shows lithostatic pressure in the middle of the test interval. These hydrostatic and lithostatic pressures are significantly different from those summarized in Table 1, as these pressures reflect the location of the downhole pressure gauge. The illustrated hydrostatic and lithostatic pressures are those that would have been measured by the gauge during each series of tests. A. First gauge deployment, Hole 948D. B. Second gauge deployment, Hole 948D. Shown are uncorrected pressure data (curve U), and pressure data with a linear correction (curve L; based on the observed pressure rise from 1.0 to 1.6 hr). The projected rise in background pressure is shown with a dotted line. The implications of this rise in background pressure are described in the text. C. First gauge deployment, Hole $949 \mathrm{C}$. D. Second gauge deployment, Hole $949 \mathrm{C}$. 
where $\rho_{\mathrm{b}}$ is bulk sediment density, and $\mathrm{P}_{\mathrm{Hsf}}$ is hydrostatic pressure at the seafloor. Lithostatic pressures were calculated at specific depths of interest based on the bulk density vs. depth function defined with the logging-while-drilling (LWD) lithodensity tool at Site 948 (Moore et al., 1995) and, based on these results and core/sample density measurements at Sites 671 and 675, used to generate a psuedodensity vs. depth relationship for Site 949 . These density vs. depth relationships are shown in Figure 4.

Overburden pressure is the difference between lithostatic and hydrostatic pressures. Because lithostatic pressure equals hydrostatic pressure at the seafloor, overburden pressure at this depth is zero. Figure 5 illustrates these concepts when applied to Holes 948D and $949 \mathrm{C}$ over the isolated parts of the holes subjected to hydrologic testing. The difference between hydrostatic and lithostatic pressures increases with depth. This increase is nonlinear, because both the lithostat and hydrostat are curves rather than lines (slopes for both curves increase with depth), although we assume that these gradients are linear for the short intervals treated in these analyses, as it greatly simplifies the calculations.

An example from Hole 948D will help to clarify the pressure vs. depth relationships. Hydrostatic pressure at the depth of the gauge, $\mathrm{P}_{\mathrm{HG}}$, was $55.2 \mathrm{MPa}$. Consider a point during testing when the measured pressure at the gauge, $\mathrm{P}_{\mathrm{MG}}$, was $58.0 \mathrm{MPa}$ (see Fig. 5A). The measured excess pressure was $\mathrm{P}_{\mathrm{MG}}-\mathrm{P}_{\mathrm{HG}}=2.8 \mathrm{MPa}$. The measured excess pressure at any time is the same everywhere in the tested zone. At the middle of the tested zone, overburden pressure, $\mathrm{P}_{\mathrm{OM}}$, was $\mathrm{P}_{\mathrm{LM}^{-}}$ $\mathrm{P}_{\mathrm{HM}}=59.5-55.6=3.9 \mathrm{MPa}$. When the measured excess pressure was $2.8 \mathrm{MPa}$, the vertical effective stress in the middle of the isolated zone was $\mathrm{P}_{\mathrm{OM}}$ minus measured excess pressure, 3.9-2.8 $=1.1 \mathrm{MPa}$.

We have normalized excess pressures through the use of an additional parameter, the modified pore pressure ratio, $\lambda *$ (Hubbert and Ruby, 1959; Davis, 1984). $\lambda^{*}$ is the ratio of the measured excess pressure to the overburden pressure in the middle of the tested zone. When the measured pressure at the gauge was $58.0 \mathrm{MPa}$, the modified pore-pressure ratio was then $\lambda^{*}=2.8 / 3.9=0.72$. For a given measured test pressure, the modified pore-pressure ratio decreases with depth in the tested zone, and the vertical effective stress increases with depth.

The values of hydrostatic and lithostatic pressure within the test interval of each hole are shown in Figure 3 along with pressure vs. time records from the four gauge deployments. In these figures, the lower horizontal line indicates hydrostatic pressure at the depth of the pressure gauge during each test. The upper shaded zone indicates calculated lithostatic pressure from the bottom to the top of the isolated part of the formation, as these pressures would have been recorded at the gauge. Actual pressures at depth would have been higher, reflecting the weight of the water column between the gauge and the depth of interest. The horizontal line within the shaded zone indicates lithostatic pressure in the middle of the isolated test interval.

During the first set of experiments in Hole 948D, test pressures were well below lithostatic (Fig. 3A). Pressures within the isolated zone began midway between hydrostatic and lithostatic during the second set of tests in Hole 948D, and exceeded lithostatic within the shallowest part of the hole during the final flow and recovery test (Fig. 3B). Data from this second set of tests in Hole 948D also were subjected to a range of pressure corrections to account for the apparent increase in background pressures with time, as described later. Pressures during the first set of tests in Hole 949C were also below lithostatic, but pressures exceeded lithostatic in the shallowest part of the hole during the final flow and recovery tests (Figs. 3C, 3D).

\section{Hydrologic Analysis Methods}

The standard hydrologic methods used to analyze these data are based on fitting measured pressure/time values to analytical solutions of a mass-conservative, diffusive flow equation. These methods generally require (1) that formation hydrologic properties remain con-

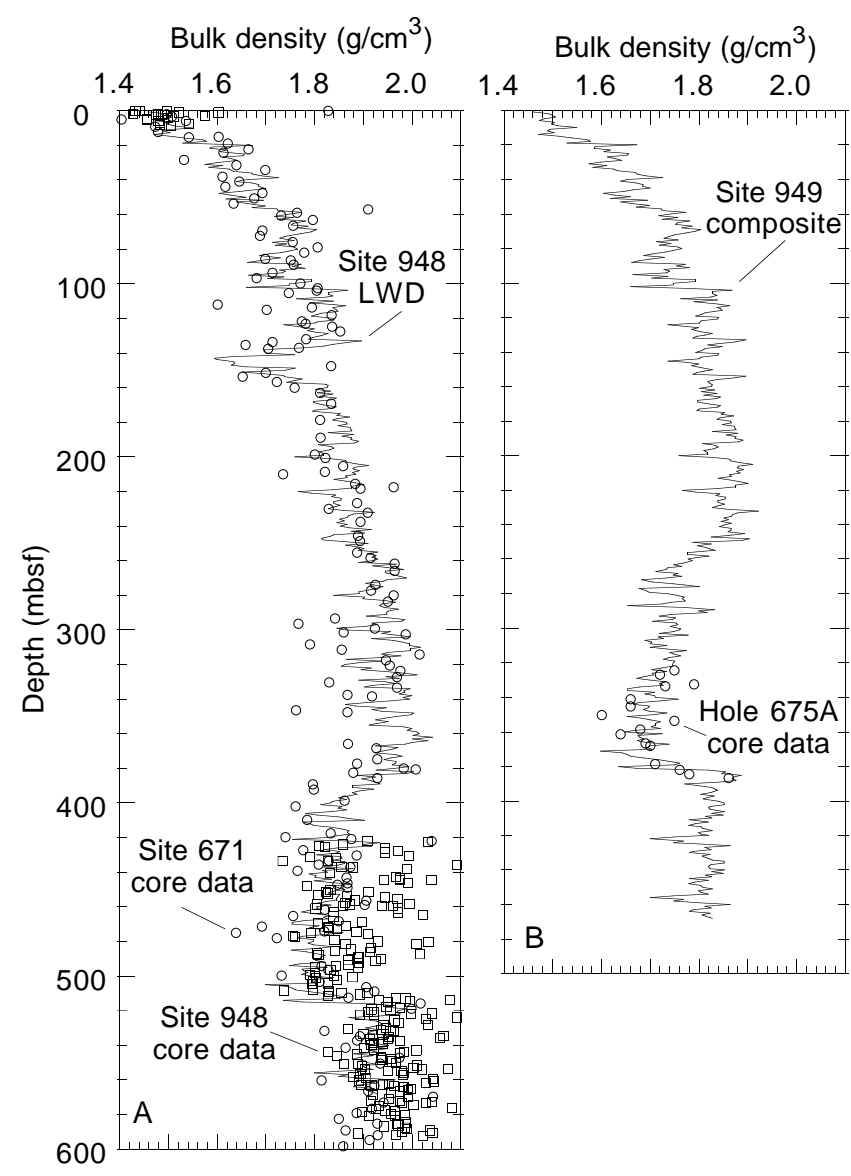

Figure 4. Density vs. depth relationships used to calculate lithostatic pressure vs. depth. A. Site 948 . The continuous curve from Site 948 is data collected with the LWD lithodensity tool (Moore et al., 1995). Measurements made on cores from Leg 156 Site 948 (Shipboard Scientific Party, 1995a) and Leg 110 Site 671 (Shipboard Scientific Party, 1988a) are shown for reference. B. Site 949. LWD data from Site 948 were segmented, depth shifted, and density shifted to create the composite pseudodensity vs. depth curve for Site 949, where no LWD data were collected. Core data from equivalent depths at ODP Leg 110 Site 675 (Shipboard Scientific Party, 1988b) are shown for reference, as the décollement was located at approximately the same depth as at Site 949. Physical properties data from cores collected at Site 949 are not shown because little sediment was recovered at this site and the material that was recovered was highly disturbed.

stant throughout individual tests, and (2) that the background fluid pressure during each test be fixed so that all pressure changes can be attributed to the tests themselves. In our analyses, we initially neglect an explicit pressure dependence of hydrologic properties during the tests themselves, noting that differences in properties between tests are greater than the changes that occur during the individual tests. Additional assumptions in these analyses include radial, Darcian flow to and from the borehole (with or without vertical leakage into or out of surrounding confining units), constant fluid viscosity during the tests (based on direct measurements of fluid temperature and pressure), and an idealized isotropic and homogeneous representation of the formation around the borehole. The calculations thus provide equivalent porous medium permeabilities, described as bulk permeabilities, allowing comparison with other seafloor and terrestrial data.

Pulse tests were analyzed using the method of Cooper et al. (1967) and Bredehoeft and Papadopulos (1980) for confined aquifers. System compressibilities were calculated directly from observations, as 
Figure 5. Pressure vs. depth trends in holes tested during Leg 156 packer experiments. The construction of these curves and identification of locations of specific points is discussed in the text. Hydrostatic curves are based on observations and calculations of water density vs. temperature and pressure (depth), whereas the lithostatic curves are based on LWD bulk density curves shown in Figure 4. Specific pressure points are identified as $\mathrm{P}_{\mathrm{XY}}$, where $\mathrm{X}$ indicates the type of pressure $(\mathrm{H}=$ hydrostatic, $\mathrm{L}=$ lithostatic, $\mathrm{O}=$ overburden, $\mathrm{M}=$ measured $)$ and $\mathrm{Y}$ indicates location $(\mathrm{B}=$ base of isolated interval, $\mathrm{M}=$ middle of isolated interval, $\mathrm{T}=$ top of isolated interval, $\mathrm{G}=$ gauge depth). A. Hole 948D. Two additional concepts are illustrated with this figure. Measured excess pressure is the pressure in

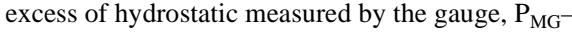
$\mathrm{P}_{\mathrm{HG}}$. This measured excess pressure is subtracted from the overburden pressure (at a depth of interest) to determine vertical effective stress. B. Hole 949C.
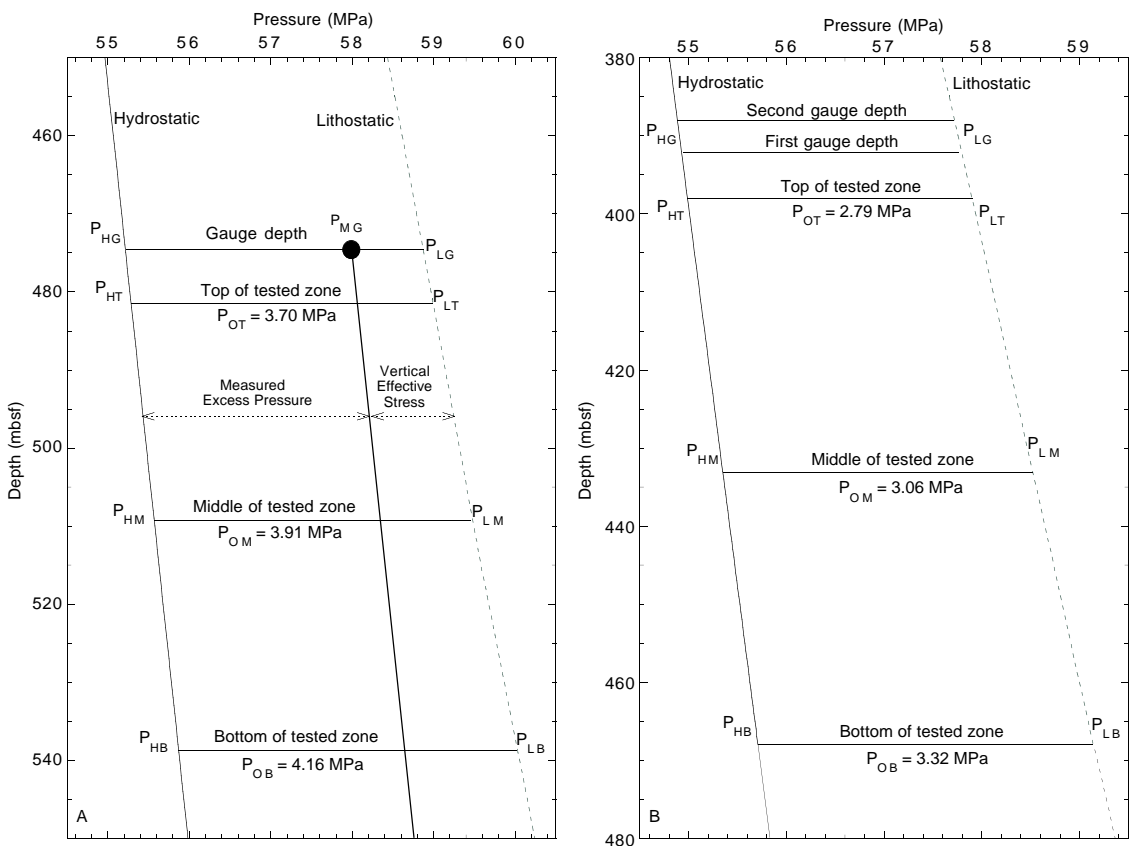

Table 2. Summary of volume and compressibility calculations for pulse tests.

\begin{tabular}{|c|c|c|c|c|c|c|}
\hline Hole & $\begin{array}{c}\text { Gauge } \\
\text { deployment }\end{array}$ & Test ID & $\begin{array}{l}\text { Isolated } \\
\text { volume } \\
\left(\mathrm{m}^{3}\right)\end{array}$ & $\begin{array}{c}\text { Pulse } \\
\text { volume } \\
\left(\mathrm{m}^{3}\right)\end{array}$ & $\begin{array}{c}\text { Pressure } \\
\text { change } \\
(\mathrm{MPa})\end{array}$ & $\begin{array}{c}\text { Compressibility } \\
\left(\mathrm{Pa}^{-1}\right)\end{array}$ \\
\hline \multirow[t]{6}{*}{ 948D } & 1 & 1 & 67.93 & $4.0 \times 10^{-2}$ & 0.650 & $0.9 \times 10^{-9}$ \\
\hline & & 2 & 67.93 & $8.0 \times 10^{-2}$ & 0.800 & $1.5 \times 10^{-9}$ \\
\hline & 2 & 6 & 67.93 & NA & NA & $4.5 \times 10^{-9} *$ \\
\hline & & 7 & 67.93 & $3.9 \times 10^{-2}$ & 0.226 & $2.6 \times 10^{-9}$ \\
\hline & & 8 & 67.93 & $7.8 \times 10^{-2}$ & 0.286 & $4.0 \times 10^{-9}$ \\
\hline & & 9 & 67.93 & $1.2 \times 10^{-1}$ & 0.256 & $6.8 \times 10^{-9}$ \\
\hline \multirow[t]{4}{*}{$949 \mathrm{C}$} & 1 & 1 & 67.28 & NA & NA & $3.3 \times 10^{-9 *} *$ \\
\hline & & 5 & 67.28 & $1.2 \times 10^{-1}$ & 0.580 & $3.0 \times 10^{-9}$ \\
\hline & & 6 & 67.28 & $1.2 \times 10^{-1}$ & 0.450 & $3.9 \times 10^{-9}$ \\
\hline & & 7 & 67.28 & $1.4 \times 10^{-1}$ & 0.650 & $3.1 \times 10^{-9}$ \\
\hline \multirow[t]{2}{*}{$949 \mathrm{C}$} & 2 & 10 & 67.28 & NA & NA & $7.2 \times 10^{-9 *}$ \\
\hline & & 11 & 67.28 & $7.8 \times 10^{-2}$ & 0.160 & $7.2 \times 10^{-9}$ \\
\hline
\end{tabular}

Notes: The isolated volume during each test includes open and screened hole below the packer, the annulus between $10-3 / 4$ in and $13-3 / 8$ in casings, the drill string from the packer to the rig floor, and the pipe volume from the rig floor to the mud pumps. Pulse volume is the total volume of fluid pumped into or recovered from the isolated interval during injection and withdrawal tests, respectively. Pressure change is the difference in pressure immediately before and after applying the fluid pulse, as measured with the downhole gauge. NA $=$ not applicable ${ }^{*}=$ pulse tests initiated by setting the packer element, during which the volume of water pumped into the isolated zone is unknown. The compressibilities used to interpret these tests are the average of subsequent compressibilities from the same set of pulse tests.

$(\Delta V / V) / \Delta P$ (Neuzil, 1982), where $P$ is pressure and $V$ is volume (Table 2). Pulse tests examine only the area immediately adjacent to the borehole and are considered less reliable than flow tests.

Flow and recovery were interpreted using the Theis (1935) solution. The leaky aquifer solutions of Hantush and Jacob (1955) and Hantush (1960), the large well solution (with well storage) of Papadopulos and Cooper (1967), and the solution of Moench (1985), which includes both large well and leaky aquifer components, were also examined for applicability with these data. Recovery test data were analyzed by accounting for remaining residual pressure from preceding flow tests and applying a correction to the subsequent recovery period. Recovery tests following periods of flow into the formation (as well as flow tests that included flow out of the formation) were inverted so that the data included an overall increase in pressure with time. Recovery following fluid flow out of the formation required no inversion. Once corrected, data from recovery tests were analyzed with the same methods as the flow tests.

We took two end-member approaches to analyzing flow and recovery tests. We first attempted to fit all the data with a Theis (1935) solution, selecting segments of the pressure vs. time records that fit this simple model. This approach was used to allow for the calculation of formation properties as they may have changed with time. We also applied the more complex models listed above to those records (1) that did not result in a satisfactory fit to the Theis curve over much of a test, and (2) that were consistent enough with another model to justify such interpretation. Neither of these two interpretive approaches, allowing properties to change with time by selecting short data segments, or assuming that properties remained constant with time and applying more complex models, can be validated through comparison with the pressure vs. time data alone, so results of both approaches are considered in the remainder of this paper.

Pumping rates and test durations for flow and recovery tests are listed in Table 3. Results of most packer tests in Holes 948D and 949C (incorporating comparisons between the Theis model and flow and recovery tests) are summarized in Tables 4 and 5 and illustrated in Figures 6-11. A summary of analyses comparing several flow tests to a leaky aquifer model are presented in Table 6 and illustrated in Figure 12 . 
Table 3. Summary of pumping rates and durations for flow and recovery tests.

\begin{tabular}{ccccc}
\hline Hole & $\begin{array}{c}\text { Gauge } \\
\text { deployment }\end{array}$ & Test ID & $\begin{array}{c}\text { Flow rate } \\
\text { (L/s) }\end{array}$ & $\begin{array}{c}\text { Test duration } \\
(\mathrm{s})\end{array}$ \\
\hline 948D & 1 & 3 & 0.45 & 600 \\
& 2 & 4 & NA & 2060 \\
& & 10 & 2.0 & 1180 \\
& & 11 & NA & 1550 \\
& & 12 & 3.9 & 1270 \\
& & 14 & NA & 1100 \\
949C & 1 & 15 & NA & 1290 \\
& & 8 & 2.0 & 1240 \\
949C & 2 & 12 & NA & 2700 \\
& & 13 & NA & 1150 \\
& & 12 & & 3640 \\
\hline
\end{tabular}

Notes: Flow rate was determined by totaling strokes $(1$ stroke $=5.2$ gal $=19.6 \mathrm{~L})$ on the cement pump and dividing by the duration of the test. Recovery tests took place when pumping had stopped. Test duration was the total time during which fluids were pumped into the hole (for flow tests) or the total time that fluid pressure was passively monitored after pumping (for recovery tests). NA = not applicable.

\section{Uncertainties in Packer Test Interpretation}

Both end-member approaches described above have limitations, particularly considering the quality of the Leg 156 data. The use of short data segments severely limits the resolution of test interpretation. In addition, aquifer test analysts prefer to use the longest possible records, including both early and late data, so that the selection of an appropriate model can be constrained. Unfortunately, none of the models provides a consistently better fit to the data from the various flow and recovery tests. The tests are simply too short, too noisy, and display too many inconsistent characteristics to be interpreted with a single model.

Another limitation of the Leg 156 pressure data is that they reflect damage to the formation surrounding the borehole because of drilling, casing, screen cleaning, and packer testing operations. Once again, the short duration of the tests precludes determining with certainty the extent of the damaged zone around the formation. We believe that damage to the formation should have resulted in shifting measured permeabilities downward (rather than upward) because of the high porosity and clay content (generally $>85 \%$ ) of the formation surrounding the screens in both holes (Shipboard Scientific Party, 1995a, 1995b; Meyer and Fisher, Chapter 27, this volume). However, we have no way of testing this hypothesis. A related problem with the present data set is that the different tests have different effective radii of investigation. Pulse tests most strongly reflect properties within the immediate vicinity of the borehole, whereas flow and recovery tests reflect properties over a greater effective radius. The quantitative radius of influence of any particular test depends on the true formation properties. Rough calculations of the radius of influence during injection tests, based on properties determined through comparison to the Theis (1935) model, suggest that the formation within $10 \mathrm{~m}$ of the boreholes should most strongly influence the measured pressure response.

A final limitation of the data from the second gauge deployment in Hole 948D is that the apparent background pressure rose during the tests, but we have no way of determining the quantitative pressure vs. time behavior outside the influence of the tests themselves. We have attempted to correct for the increase in background pressure, as described in the following section. We also considered the application of fracture-based flow and dual permeability models, but there are insufficient data to constrain the extra parameters associated with these more complex approaches.

In summary, the interpretations that follow should be viewed with caution. These are the best data available at present from this geological setting, but they require validation through additional testing and modeling. In the following pages, we describe the fits of the data to the various interpretive models. The implications of the various fits to the selection of appropriate models are discussed in the subsequent section.

\section{Results from Hole 948D}

Fifteen individual tests were attempted in Hole 948D, seven pulse tests (two withdrawal and five injection), four flow tests (one withdrawal and three injection), and four recovery tests following periods of constant flow. The pressure records from the time immediately before the packer element was inflated are different from records collected in other ODP holes (Fig. 3). First, the records are noisy, particularly during the first set of tests. Second, the records show an increase in pressure with time, even before the element was inflated; the gauges should have recorded hydrostatic pressure during this time. These two anomalous characteristics may reflect the same condition: a casing string coated with slick mud, making the effective casing diameter much narrower than intended, yet still allowing the packer element to move as the ship and drill string heaved. The noise in the record may reflect a dynamic condition associated with the long drill string and ship heave. The noise is absent only when the packer element was inflated but before the packer was set (Fig. 3). This was the only time during the tests when the isolated zone was not in hydraulic communication with the rest of the plumbing system. The gradual pressure rise before the packer was set may reflect a partial seal between the isolated zone and the hydrostatic water column, with limited communication through the sediment-packed inflation and relief ports.

Setting the packer normally results in the formation being subjected to a pulse test, as some of the fluid associated with inflating the element is forced into the isolated zone. Setting the packer for the first tests in Hole 948D does not appear to have resulted in a pulsing of the formation, perhaps because the very slow speed of the set and subsequent release of fluid through vent holes above the packer element. Whereas Tests 1 through 4 were interpreted using standard methods, no interpretation was made for Test 5 , as the screen appears to have been clogged. Background pressures for pulse Tests 1 and 2 were selected following examination of the pressure records and iterative processing using a range of values. Initial pressures for flow Test 3 and recovery Test 4 were not as important, as interpretation of these data was based on the change in pressure with time, not the initial pressure value. All data from the first gauge deployment in Hole 948D are of low quality (Fig. 6; Table 4).

Tests made during the second gauge deployment in Hole 948D (Tests 6-15) were processed following a series of pressure corrections, as follows. Background pressure rose linearly with time as the pressure gauge rested inside the packer at the start of the test (at time, $t$, of 1.0-1.6 hr, Fig. 3B). The linear shift required to keep this background pressure constant was applied to the full record (curve $L$, Fig. $3 \mathrm{~B}$ ); we believe this correction to be a conservative lower bound on the overall trend of the background pressure rise during the tests. This single correction was sufficient to remove any residual excess pressure from the individual pulse tests (i.e., after accounting for excess 
Figure 6. Analyses of test results from the first gauge deployment in Hole 948D. For the pulse tests, the indicated values for $\alpha$ correspond to the best-fitting type curve. The arrows indicate the shift in time or $\beta$ required to obtain this fit. These parameters are described by Bredehoeft and Papadopulos (1980). A. Normalized pressure vs. time and $F(\alpha, \beta)$ vs. $\beta$ for Test 1 . B. Normalized pressure vs. time and $\mathrm{F}(\alpha, \beta)$ vs. $\beta$ for Test 2 . C. Pressure vs. time during withdrawal flow Test 3 , along with Theis curve. D. Pressure vs. time during recovery Test 4, along with Theis curve. Large circles around data values indicate the first and last values that were used to determine the best-fitting Theis curves as shown. The variable $t_{0}$ is the time when pumping began for flow tests, and the time when pumping stopped for recovery tests. The data from recovery Test 4 were corrected for preceding flow Test 3 .

pressure due to the pulse tests themselves, the background pressure at the end of all pulse tests was equal to the initial value).

The reason for the increase in fluid pressure in Hole 948D is unknown, although it is likely to have been a combination of natural fluid pressure in the formation surrounding the borehole (after being subjected temporarily to hydrostatic conditions) and charging of the formation during drilling and casing operations. CORK results from Hole 949C (Becker et al., Chapter 19, this volume) suggest that natural fluid pressures in excess of hydrostatic are present within the décollement. The magnitude of the excess pressure in Hole 949C, about $1 \mathrm{MPa}$, is the same as that inferred in the same hole from packer data during Leg 156 (Shipboard Scientific Party, 1995), suggesting that drilling effects on measured pressures may have been minimal. In addition, Moore et al. (1995) interpreted LWD data in terms of excess fluid pressure (approaching lithostatic) at Site 948 as well. This would be consistent with the data collected during packer operations.

Results of tests from the second gauge deployment are illustrated in Figures 7-9. Analysis of pulse Tests 6 and 8 resulted in selection of $\alpha$ values (related to formation storage) of 3.0 and 1.0, respectively (Fig. 7). Values of $\alpha$ greater than about 0.1 indicate a dependency of the pressure decay function, $F(\alpha, \beta)$, on $\alpha \times \beta$ rather than on $\alpha$ and $\beta$
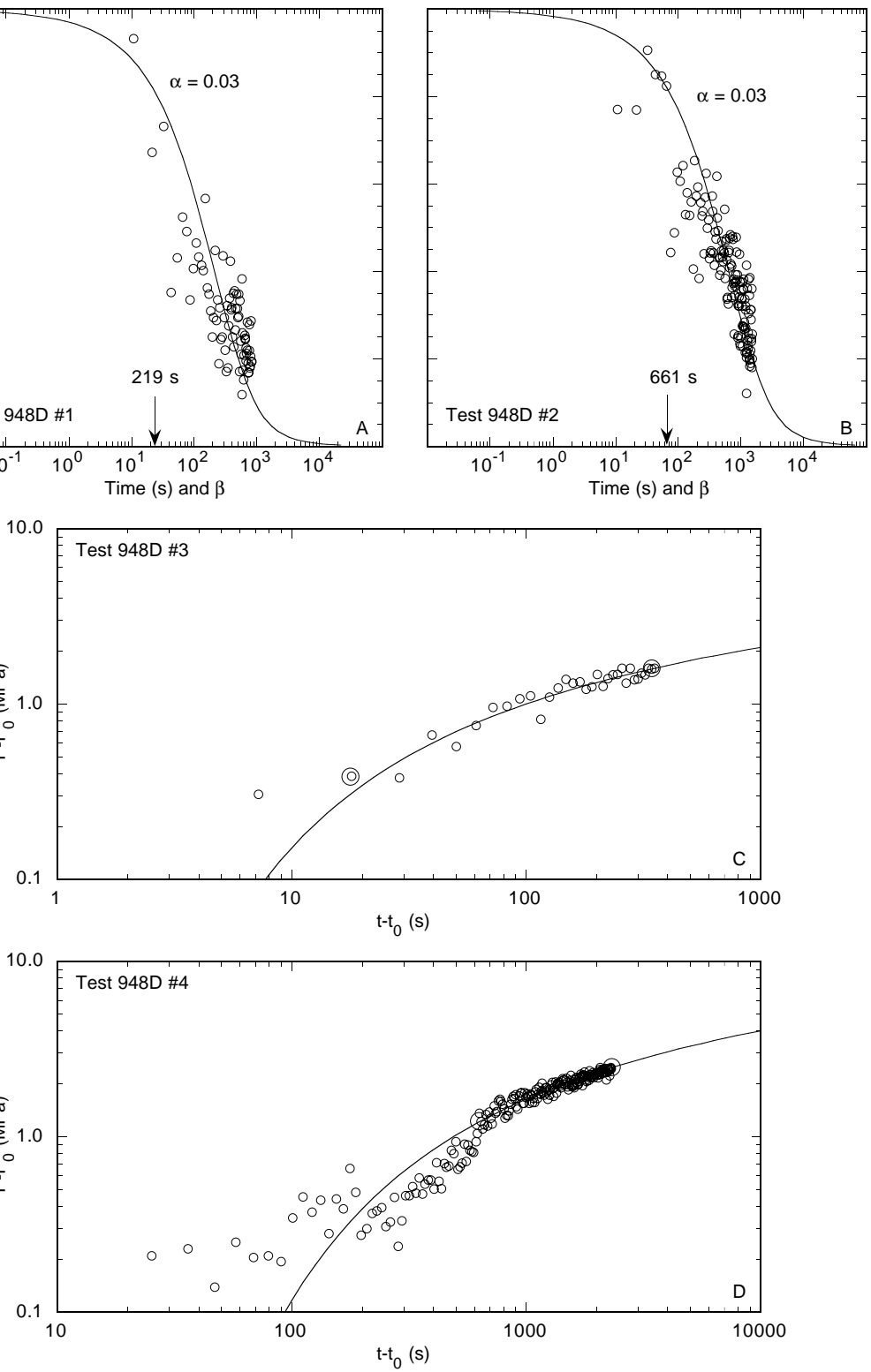

separately, limiting the applicability of the standard interpretive model (Bredehoeft and Papadopulos, 1980). A plot of these test data as $\mathrm{F}(\alpha, \beta)$ vs. $\alpha \times \beta$ indicates that the data are equally well fit with an arbitrarily large value of $\alpha$ (Fig. 8). This finding suggests that it may not be possible to determine the transmissivity of the formation from these tests with certainty, although this might be possible if appropriate values for $\alpha$ were constrained by data from other tests. Interpretations of transmissivity and bulk permeability from these tests are included in Table 4 for completeness. The consistency of these results with other test results gives somewhat greater confidence in their accuracy, although taken by themselves, Tests 6 and 8 would not be considered to be reliable.

Data from flow Test 10 provided a good fit to the standard Theis curve with all but the earliest data, whereas data from Tests 12 and 14 fit the Theis curve only over limited data intervals (Fig. 9). Figure 9 also shows a fit of early data to separate Theis curves for these last two tests. Late-time data from recovery Test 13 fits a standard Theis curve, whereas recovery Tests 11 and 15 fit the Theis model quite poorly. In Figure 9, Theis curves are shown for early- and late-time data intervals in an attempt to bracket a range of possible bulk permeabilities. Where Theis curves were fit for both early- and late-time 
Table 4. Summary of packer test results from Hole 948D.

\begin{tabular}{|c|c|c|c|c|c|c|c|c|c|c|c|c|c|c|c|}
\hline Test ID & $\begin{array}{l}\text { Test } \\
\text { type }\end{array}$ & $\begin{array}{c}\mathrm{P}_{0} \\
(\mathrm{MPa})\end{array}$ & Corr & $\begin{array}{c}\text { Pressure } \\
\text { at start } \\
(\mathrm{MPa})\end{array}$ & $\begin{array}{c}\text { Pressure } \\
\text { at end } \\
(\mathrm{MPa})\end{array}$ & $\begin{array}{c}\sigma_{\mathrm{v}}{ }^{\prime} \\
\text { at start } \\
(\mathrm{MPa})\end{array}$ & $\begin{array}{c}\sigma_{\mathrm{v}}^{\prime} \\
\text { at end } \\
(\mathrm{MPa})\end{array}$ & $\begin{array}{c}\lambda^{*} \\
\text { at start }\end{array}$ & $\begin{array}{c}\lambda^{*} \\
\text { at start }\end{array}$ & $\alpha$ & $\Delta ß$ & $\begin{array}{c}\mathrm{T} \\
\left(\mathrm{m}^{2} / \mathrm{s}\right)\end{array}$ & $\begin{array}{l}\mathrm{k}_{\mathrm{b}} \\
\left(\mathrm{m}^{2}\right)\end{array}$ & S & $\begin{array}{c}\mathrm{U}_{\mathrm{e}} \\
\pm \log \text { units }\end{array}$ \\
\hline 1 & $\mathrm{P}_{\mathrm{w}}$ & 56.9 & None & 56.475 & 56.720 & 2.685 & 2.440 & 0.315 & 0.377 & 0.03 & 2.34 & $1.0 \times 10^{-6}$ & $2.4 \times 10^{-15}$ & $1.7 \times 10^{-4}$ & $>1.0$ \\
\hline 2 & $\mathrm{P}_{\mathrm{w}}^{\mathrm{w}}$ & 57.0 & None & 56.300 & 56.640 & 2.860 & 2.520 & 0.270 & 0.357 & 0.03 & 2.82 & $3.3 \times 10^{-7}$ & $8.0 \times 10^{-16}$ & $2.8 \times 10^{-4}$ & $>1.0$ \\
\hline 3 & $F_{w}^{w}$ & NA & None & 56.330 & 55.400 & 2.372 & 3.678 & 0.278 & 0.040 & NA & NA & $7.4 \times 10^{-7}$ & $1.8 \times 10^{-15}$ & $6.6 \times 10^{-4}$ & $>1.0$ \\
\hline 4 & $\mathrm{R}_{\mathrm{w}}$ & NA & None & 55.520 & 56.860 & 3.208 & 2.300 & 0.071 & 0.413 & NA & NA & $3.3 \times 10^{-7}$ & $8.0 \times 10^{-16}$ & $5.4 \times 10^{-3}$ & 1.0 \\
\hline 6 & $P_{i}$ & 57.4 & $\mathrm{~L}$ & 57.892 & 57.528 & 1.268 & 1.632 & 0.676 & 0.583 & 3.0 & 3.45 & $1.0 \times 10^{-6}$ & $2.4 \times 10^{-15}$ & $5.5 \times 10^{-2}$ & 1.0 \\
\hline 7 & $P_{i}$ & 57.4 & $\mathrm{~L}$ & 57.675 & 57.571 & 1.485 & 1.589 & 0.661 & 0.594 & 0.03 & 2.55 & $3.1 \times 10^{-6}$ & $7.4 \times 10^{-15}$ & $1.6 \times 10^{-4}$ & 1.0 \\
\hline 8 & $\mathrm{P}_{\mathrm{i}}$ & 57.4 & $\mathrm{~L}$ & 57.776 & 57.676 & 1.384 & 1.484 & 0.647 & 0.621 & 1.0 & 3.51 & $2.8 \times 10^{-7}$ & $6.6 \times 10^{-16}$ & $2.4 \times 10^{-2}$ & 1.0 \\
\hline 9 & $\mathrm{P}_{\mathrm{i}}$ & 57.4 & $\mathrm{~L}$ & 58.012 & 57.785 & 1.148 & 1.375 & 0.707 & 0.649 & 0.1 & 3.18 & $1.3 \times 10^{-6}$ & $3.1 \times 10^{-15}$ & $4.2 \times 10^{-3}$ & 1.0 \\
\hline 10 & $\mathrm{~F}_{\mathrm{i}}$ & NA & $\mathrm{L}$ & 58.151 & 58.359 & 1.148 & 0.621 & 0.707 & 0.841 & NA & NA & $1.4 \times 10^{-5}$ & $3.4 \times 10^{-14}$ & $4.3 \times 10^{-3}$ & 0.5 \\
\hline $11 \mathrm{~A}$ & $\mathrm{R}_{\mathrm{i}}$ & NA & $\mathrm{L}$ & 58.495 & 58.451 & 0.647 & 0.691 & 0.835 & 0.824 & NA & NA & $2.9 \times 10^{-5}$ & $6.9 \times 10^{-14}$ & $4.6 \times 10^{-2}$ & $>1.0$ \\
\hline $11 \mathrm{~B}$ & $\mathrm{R}_{\mathrm{i}}$ & NA & $\mathrm{L}$ & 58.270 & 58.129 & 0.895 & 1.031 & 0.772 & 0.737 & NA & NA & $3.1 \times 10^{-6}$ & $7.3 \times 10^{-15}$ & $8.9 \times 10^{-2}$ & $>1.0$ \\
\hline $12 \mathrm{~A}$ & $\mathrm{~F}_{\mathrm{i}}$ & NA & $\mathrm{L}$ & 58.487 & 58.748 & 1.017 & 0.637 & 0.740 & 0.837 & NA & NA & $3.7 \times 10^{-6}$ & $8.9 \times 10^{-15}$ & $2.2 \times 10^{-2}$ & $>1.0$ \\
\hline $12 \mathrm{~B}$ & $\mathrm{~F}_{\mathrm{i}}$ & NA & $\mathrm{L}$ & 58.487 & 58.748 & 0.637 & 0.412 & 0.837 & 0.895 & NA & NA & $4.1 \times 10^{-5}$ & $9.2 \times 10^{-14}$ & $1.2 \times 10^{-3}$ & 0.75 \\
\hline 13 & $\mathrm{R}_{\mathrm{i}}$ & NA & $\mathrm{L}$ & 58.709 & 58.555 & 0.451 & 0.559 & 0.885 & 0.857 & NA & NA & $4.1 \times 10^{-5}$ & $9.7 \times 10^{-14}$ & $1.8 \times 10^{-2}$ & 0.75 \\
\hline $14 \mathrm{~A}$ & $F_{i}$ & NA & $\mathrm{L}$ & 58.598 & 58.831 & 0.591 & 0.405 & 0.849 & 0.897 & NA & NA & $2.6 \times 10^{-5}$ & $6.1 \times 10^{-14}$ & $7.7 \times 10^{-2}$ & $>1.0$ \\
\hline $14 \mathrm{~B}$ & $\mathrm{~F}_{\mathrm{i}}$ & NA & $\mathrm{L}$ & 58.815 & 58.971 & 0.394 & 0.276 & 0.899 & 0.930 & NA & NA & $4.3 \times 10^{-5}$ & $1.0 \times 10^{-13}$ & $4.8 \times 10^{-2}$ & 0.75 \\
\hline $15 \mathrm{~A}$ & $\mathrm{R}_{\mathrm{i}}$ & NA & $\mathrm{L}$ & 59.037 & 59.014 & 0.118 & 0.141 & 0.970 & 0.964 & NA & NA & $1.4 \times 10^{-4}$ & $3.5 \times 10^{-13}$ & $1.5 \times 10^{-1}$ & $>1.0$ \\
\hline $15 \mathrm{~B}$ & $\mathrm{R}_{\mathrm{i}}$ & NA & $\mathrm{L}$ & 58.995 & 58.970 & 0.172 & 0.207 & 0.956 & 0.947 & NA & NA & $2.3 \times 10^{-5}$ & $5.5 \times 10^{-14}$ & $5.3 \times 10^{-1}$ & $>1.0$ \\
\hline
\end{tabular}

Notes: $\mathrm{P}_{0}=$ initial baseline pressure assumed for start of pulse test. Corr $=$ pressure correction applied to full record following selection of $\mathrm{P}_{0}$. Pressures were measured at the start and end of the time interval selected for interpretation. Vertical effective stress was measured at the pressures at the start and end of time interval selected for interpretation, based on calculations described in text and shown as pressure vs. depth trends in Figure 5A. Measured pressures are adjusted to reflect the depth at the center of the isolated interval. Modified pore-pressure ratio at the measured pressures at the start and end of time interval selected for interpretation, based on calculations described in text and shown as pressure vs. depth trends in Figure 5A. Measured pressures are adjusted to reflect the depth at the center of the isolated interval. $\alpha=$ type curve parameter (Bredehoeft and Papadopulos, 1980) that best fits selected data. $\Delta B=$ shift of type curve required to best fit selected data. $T=$ transmissivity; $\mathrm{k}_{\mathrm{b}}=$ bulk permeability, assuming a tested zone $70 \mathrm{~m}$ thick; $\mathrm{S}=$ storage coefficient; and $\mathrm{U}_{\mathrm{e}}=$ estimated uncertainties in transmissivity and bulk permeabilities, expressed as $\log$ units. $\mathrm{P}=$ pulse test; $\mathrm{F}=$ flow test; subscript $\mathrm{i}=$ injection; and subscript $\mathrm{w}=$ withdrawal. $\mathrm{L}=$ linear correction (as described in text) based on consistent pressure increase during time after gauge landed in packer but before packer element was set (approximate relative time interval $1.0-1.6 \mathrm{hr}$ on Figure $7 \mathrm{~B}) . \mathrm{NA}=$ not applicable.

data segments, the resulting values for both data segments are listed in Table 4.

\section{Results from Hole 949C}

Thirteen total packer tests were attempted in Hole 949C, eight pulse tests (two withdrawal and six injection), three flow tests (one withdrawal and two injection), and two recovery tests following periods of constant flow. Results of these tests are summarized in Tables 5 and 6 and illustrated in Figures 10, 11, and 12. Once again, the pressure records are noisier than typical records from ODP packer tests in basement holes. Upon inflation of the packer and setting of the element for the first time in Hole 949C, pressure rose immediately by about $1.5 \mathrm{MPa}$ over hydrostatic and then decayed (Fig. 3C), providing an apparently reliable pulse test of the isolated zone (Fig. 10A). Subsequent withdrawal pulse tests (Fig. 3C) were unsuccessful, most likely because the formation was unable to supply sufficient fluid to keep up with fluid release at the rig floor. In fact, an attempt to run a constant rate withdrawal test (Test 4; Fig. 3C) failed when the rig floor plumbing emptied completely. Tests $2-4$ in Hole 949C were not interpreted for this reason. Pressures recorded by the downhole gauge during the next 90 min were consistently 175-185 kPa greater than hydrostatic, perhaps reflecting some lower limit on the formation fluid pressure immediately adjacent to the borehole during this time, although earlier and later data suggest that this value is below the natural formation fluid pressure. Injection pulse tests that followed refilling the stand pipe (Tests 5, 6, and 7; Fig. 3C) are of uniformly poor quality and could not be interpreted reliably. An interpretation of Test 5 is included for completeness, although this result has very high uncertainty (Table 5; Fig. 10B). Late-time data from a final constant-rate flow test seem to produce a good fit to a Theis curve (Test 8; Fig. 10C), although a subsequent recovery test did not (Test 9; Fig. 10D).

Four more tests were attempted with a second deployment of the pressure gauge in Hole 949C, producing data of varying reliability (Figs. 3D, 11; Table 5). Two injection pulse tests gave internally consistent responses (Tests 10 and 11), as did injection flow and recovery tests (Tests 12 and 13). It appears that lithostatic pressure at the top of the isolated zone may have been exceeded during the final stage of the flow test and at the start of the recovery test (Fig. 3D), although data from these time periods were not used for quantitative analysis (Figs. 11C, 11D).

\section{Additional Interpretation of Flow Tests}

Leg 156 flow tests were subjected to additional analyses in an attempt to fit longer data sections from each test. Data from flow Test 10 in Hole 948D fit a standard Theis curve quite well (Fig. 9A). Although this test can also be fit to other models, the resulting bulk properties (T and $\mathrm{S}$ ) are little different from those of the best-fitting Theis curve. The simplest of these additional models, the Hantush and Jacob (1955) leaky aquifer model, can be fit to early- and some late-time data from flow Test 12 (Fig. 12A). This fit is consistent with an apparent bulk permeability about $40 \%$ lower than that of Theis fit to late-time data (Fig. 12A, Table 6). However, the fit of the Hantush and Jacob model to the late-time data is actually quite poor (Fig. 12A). An abrupt change in slope of the pressure vs. time record, with an apparent drop in pressure at about $600 \mathrm{~s}$, is consistent with a rapid increase in formation permeability and/or storage.

The Hantush and Jacob model also can be fit to much of the data from flow Test 14, again with the exception of the late test data. In this case, the data deviate from the type curve by rising above it after about $600 \mathrm{~s}$. This inflection could reflect lateral heterogeneity in the formation or changes in formation properties with time. The best-fitting Hantush and Jacob model (Fig. 12B) includes a bulk permeability about $75 \%$ lower than that associated with the best-fitting Theis curve based on middle-time interval of the data set (Tables 4, 6; Fig. 12B).

Late-time data from flow Test 8 in Hole $949 \mathrm{C}$ also can be fit to a variety of models, although none of these provide a satisfying fit to the early-time data (Fig. 12C; Table 6). The Hantush and Jacob model also fits the late-time data from flow Test 12, with an apparent bulk permeability about $40 \%$ lower than suggested by the best-fitting Theis curve. Once again, the early and late data are difficult to fit with a single curve.

Other analytical models could be used to interpret the flow test data. The Hantush (1960) model includes storage within confining layer, and the Moench (1985) model allows for confining layer stor- 
Figure 7. Analyses of pulse test results from the second gauge deployment in Hole 948D. The indicated values for $\alpha$ correspond to the best-fitting type curve. The arrows indicate the shift in time or $\beta$ required to obtain this fit. These parameters are described by Bredehoeft and Papadopulos (1980). A. Normalized pressure vs. time and $\mathrm{F}(\alpha, \beta)$ vs. $\beta$ for Test 6. B. Normalized pressure vs. time and $F(\alpha, \beta)$ vs. $\beta$ for Test 7. C. Normalized pressure vs. time and $F(\alpha, \beta)$ vs. $\beta$ for Test 8 . D. Normalized pressure vs. time and $\mathrm{F}(\alpha, \beta)$ vs. $\beta$ for Test 9 .
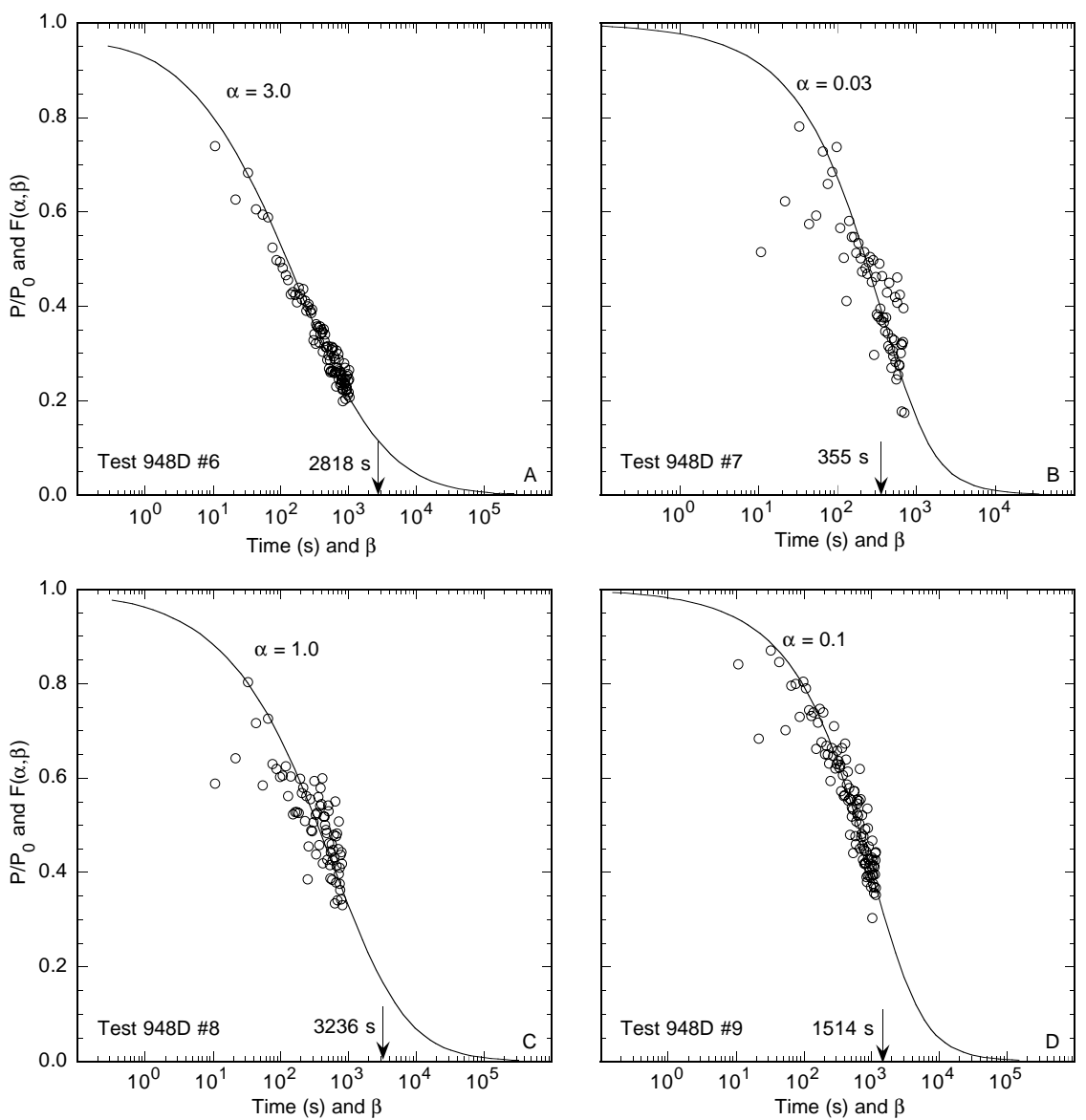

Figure 8. Comparison of two pulse test results from Hole 948 Dy plotting $F(\alpha, \beta)$ vs. $\beta$ and vs. $\alpha \times \beta$ (Bredehoeft and Papadopulos, 1980). A. Pulse Test 6 . The type curve for $\alpha=3.0$ has been left unshifted, for comparison, whereas the shift for the $\alpha \geq 10.0$ curve is shown with the annotated arrow. B. Pulse Test 8 . The type curve for $\alpha=1.0$ has been left unshifted, for comparison, whereas the shift for the $\alpha \geq 10.0$ curve is shown with the annotated arrow. These plots illustrate that virtually any large value for $\alpha$ can be used to match the observed data, making selection of an appropriate value difficult.
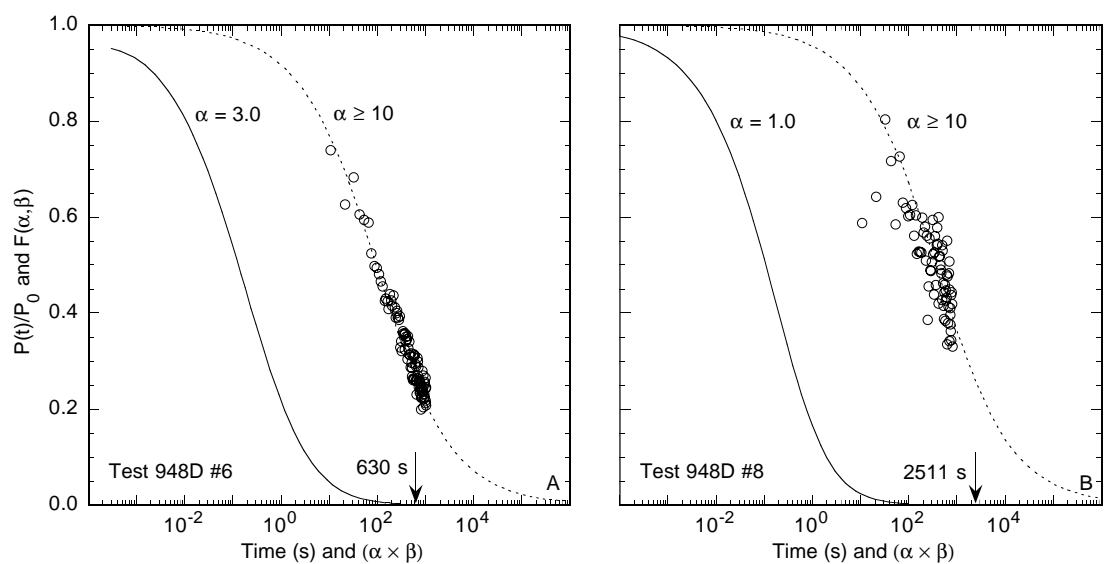

age, large-diameter wells, well storage, and well skin effects. Estimated transmissivity and storativity values based on the Hantush (1960) model were essentially identical to the Hantush and Jacob (1955) results presented earlier. We were unable to obtain a better fit to the data using the Moench (1985) model, however, as the observations are inconsistent with the type curves for data collected in a pumping well at early times.

Attempts to fit recovery test data with various alternative models were unsuccessful. Data from many of recovery tests that did not fit the Theis model tend to form a linear distribution when plotted in log/ log space (Figs. 9, 10). Hantush and Jacob (1955), Hantush (1960), Papadopulos and Cooper (1967), and Moench (1985) models can be fit to these data, but the fits are essentially unconstrained (i.e., allow selection of properties over many orders of magnitude) because there is no change in data slope to match with the type curves. This change in slope is important for making a confident match between observations and models. For this reason, no matches between these additional models and recovery data are presented.

Another parameter typically used to aid with interpretation of aquifer tests is storativity, a measure of the capacity of the isolated system to accept or yield water that is held in pore spaces in the formation. In confined aquifers, storativity comprises two distinct components: fluid compressibility and aquifer frame compressibility. Storativities for confined aquifers in solid rock are usually less than 0.001 . The storativities predicted from fitting Leg 156 data to Theis curves are generally greater than this (Tables 4,5 ), but are not unrea- 

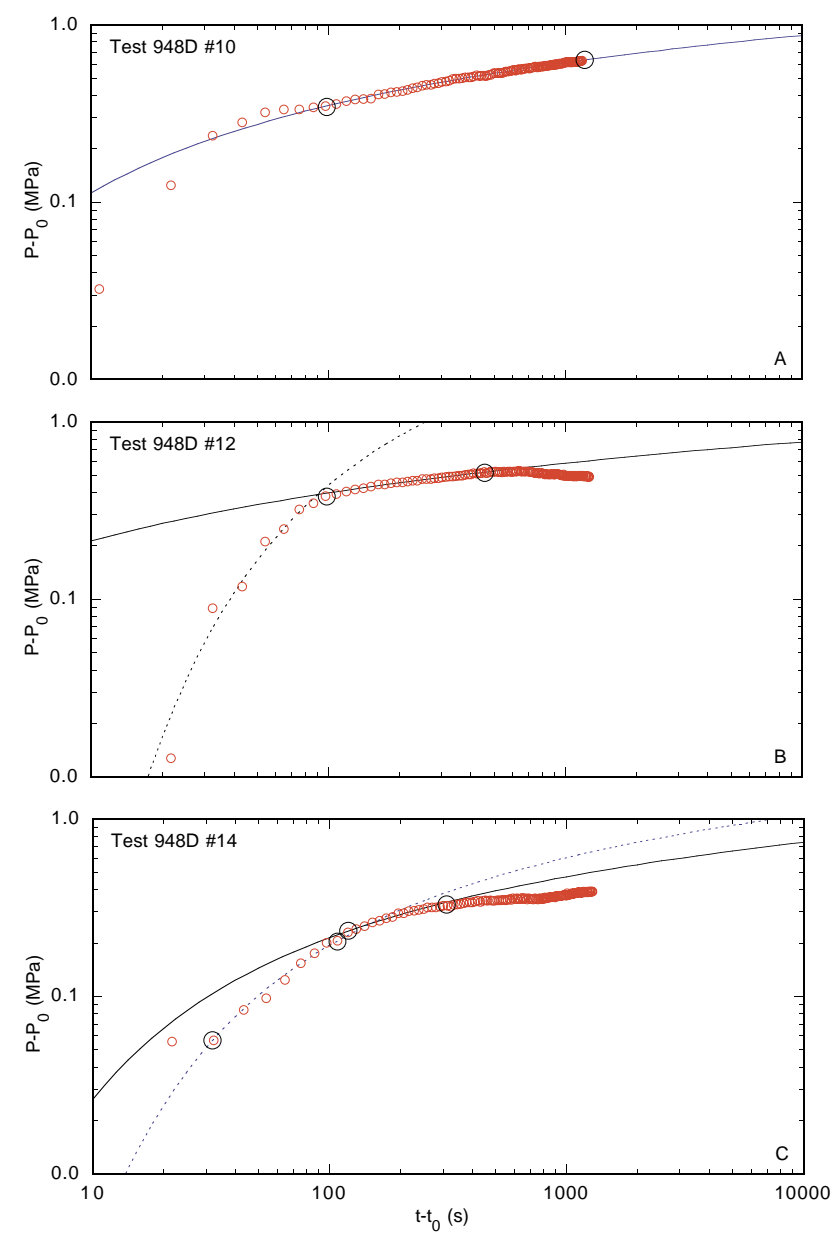
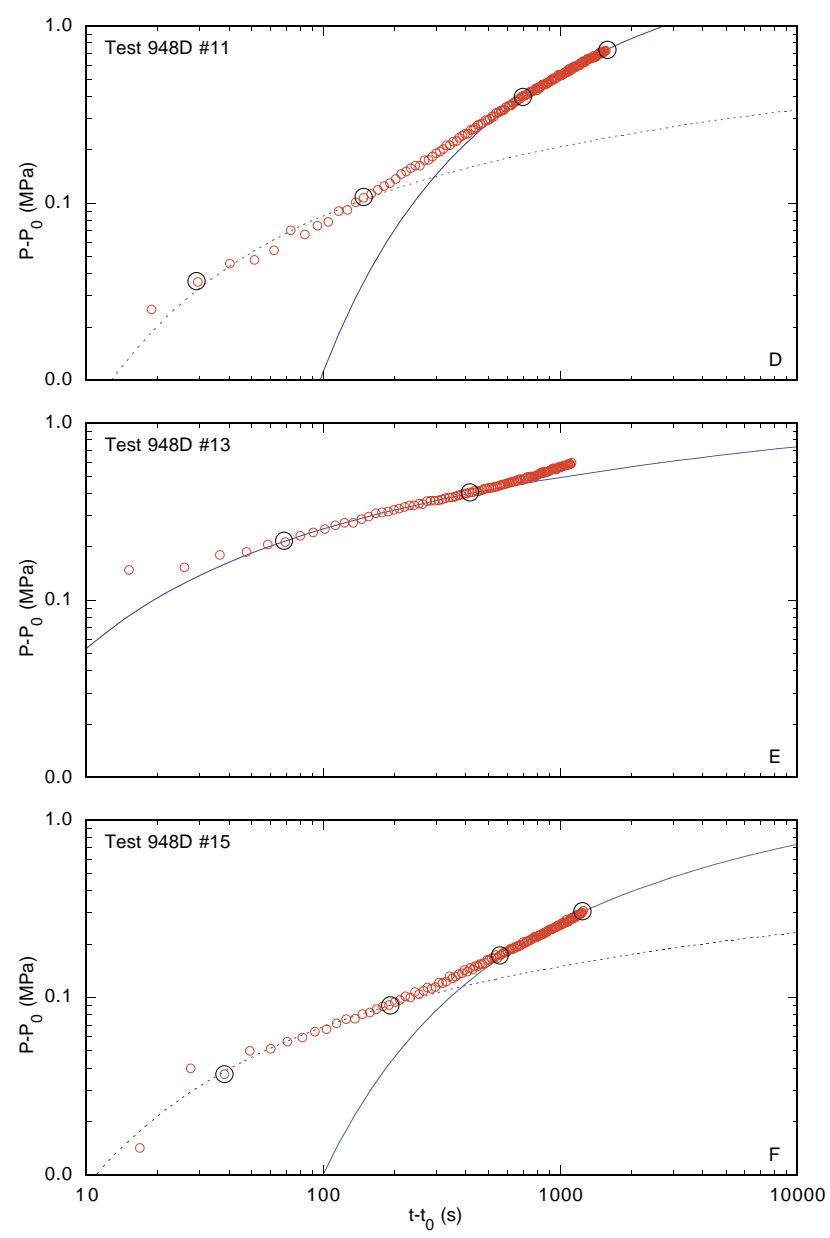

Figure 9. Analyses of flow and recovery test results from the second gauge deployment in Hole 948D. Test data are plotted along with best-fitting Theis curves. Dotted lines are fit to early-time data, while solid lines are fit to later time data. Large circles around data values indicate the first and last values that were used to constrain the best-fitting Theis curves. Recovery tests were corrected for initial flow tests, and then inverted so that pressures increased with time rather than decreased. The variable $t_{0}$ is the time when pumping began for flow tests, and the time when pumping stopped for recovery tests. A. Flow Test 10 . B. Flow Test 12. C. Flow Test 14. D. Recovery Test 11. E. Recovery Test 13. F. Recovery Test 15.

sonable for unconsolidated, clayey sediments (having a highly compressive frame) with high porosity. Similarly high storativities are estimated from matching the data to leaky aquifer and other models as well, although the various models yield a range of storativities (Table 6).

\section{DISCUSSION}

\section{Packer Test Interpretations}

While the fits of Leg 156 packer data to the idealized models discussed above are not exhaustive, they illustrate the difficulty in interpreting many of these tests with a single flow model. The Hantush and Jacob (1955) model seems to fit both early and some late data from two of the flow tests, although this model deviates from the data at late times (Figs. 12A, 12B). Other data are fit quite well with a Theis curve (i.e., Hole 948D, flow Test 10). It is more difficult to select an appropriate model for other flow tests, because the data segments consistent with any model are so short.

In general, the standard type curves do not match the data from the recovery tests, with the exception of Theis model fits to recovery Test 13 (949C) and perhaps recovery Test 4 (948D). The apparent linearity of the data from the other recovery tests following injection flow tests, when plotted on log/log space, could reflect a decrease in per- meability with time while pressure in the formation drops (Figs. 9, 10), which would be consistent with the observed deviation from the Theis model.

Selected packer test results from Holes 948D and 949C are summarized in Figure 13, based on the interpretation that formation properties change with fluid pressure, with a range of pressure values shown for each test. These ranges include the pressures measured over the parts of the records listed in Tables 4 and 5 that were used for interpretation of each test through matching to the Theis model. All interpretations are included in this figure, even those with which we have low confidence. The results of the three tests for which the Hantush and Jacob (1955) model can be fit to early- and late-time data (Fig. 12; Table 6) also are shown for comparison.

The data from each hole fall into two general groups (Fig. 13). Most data follow general trends of $\log /$ bulk permeability vs. vertical effective stress and $\mathrm{log} / \mathrm{bulk}$ permeability vs. modified pore-pressure ratio. These bulk permeabilities extend over a range of $6 \times 10^{-16} \mathrm{~m}^{2}$ to $6 \times 10^{-13} \mathrm{~m}^{2}$, a vertical effective stress range of $1.7-0.1 \mathrm{MPa}$, and a modified pore-pressure ratio of $0.45-0.95$.

A smaller number of test results fall off this trend, with bulk permeability values close to $10^{-15} \mathrm{~m}^{2}$, vertical effective stress values ranging from 1.5 to $3.7 \mathrm{MPa}$, and modified pore-pressure ratios of 0.15-0.55. All of the test data that fall into this second cluster of points are of poor quality, as listed in Tables 4 and 5. These are the 
Figure 10. Analyses of test results from the first gauge deployment in Hole 949C. For the pulse tests, the indicated values for $\alpha$ correspond to the best-fitting type curve. The arrows indicate the shift in time or $\beta$ required to obtain this fit. These parameters are described by Bredehoeft and Papadopulos (1980). A. Normalized pressure vs. time and $F(\alpha, \beta)$ vs. $\beta$ for Test 1. B. Normalized pressure vs. time and $F(\alpha, \beta)$ vs. $\beta$ for Test 5. C. Pressure vs. time during withdrawal flow Test 8. D. Pressure vs. time during recovery Test 9. Dotted line shows the fit with early-time data; solid curve is fit to later time data. Large circles around data values indicate the first and last values that were used to determine the best-fitting Theis curves as shown. Recovery Test 9 was corrected for preceding flow Test 8 , and then inverted so that pressures increased with time rather than decreased. The variable $\mathrm{t}_{0}$ is the time when pumping began for flow tests, and the time when pumping stopped for recovery tests.
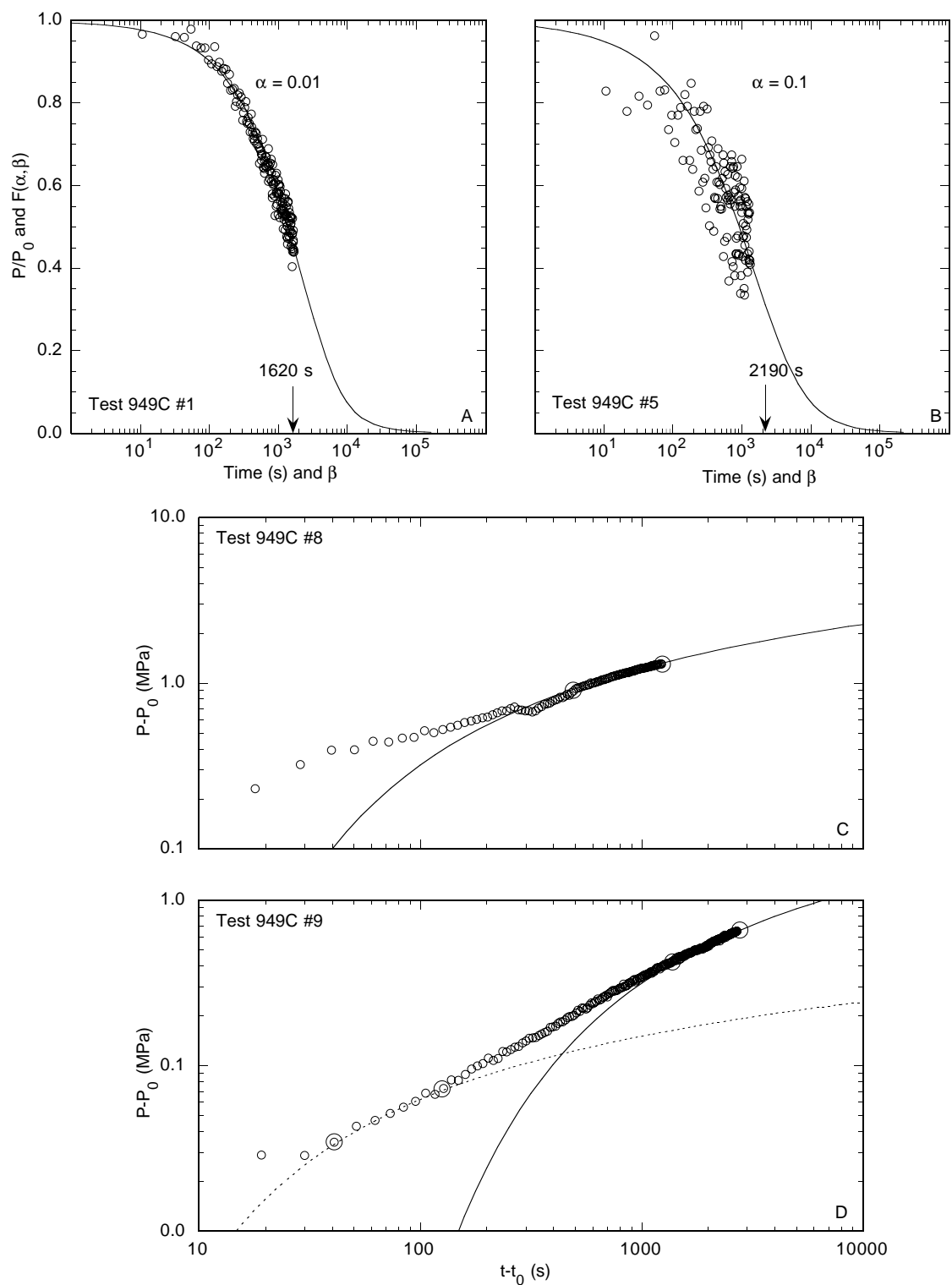

Table 5. Summary of packer test results from Hole 949C.

\begin{tabular}{|c|c|c|c|c|c|c|c|c|c|c|c|c|c|c|c|}
\hline Test ID & $\begin{array}{l}\text { Test } \\
\text { type }\end{array}$ & $\begin{array}{c}\mathrm{P}_{0} \\
(\mathrm{MPa})\end{array}$ & Corr & $\begin{array}{l}\text { Pressure } \\
\text { at start } \\
(\mathrm{MPa})\end{array}$ & $\begin{array}{c}\text { Pressure } \\
\text { at end } \\
(\mathrm{MPa})\end{array}$ & $\begin{array}{c}\sigma_{\mathrm{v}}{ }^{\prime} \text { at } \\
\text { start } \\
(\mathrm{MPa})\end{array}$ & $\begin{array}{c}\sigma_{\mathrm{v}}^{\prime} \text { at } \\
\text { end } \\
(\mathrm{MPa})\end{array}$ & $\begin{array}{c}\lambda * \\
\text { at start }\end{array}$ & $\begin{array}{c}\lambda * \\
\text { at end }\end{array}$ & $\alpha$ & $\Delta \beta$ & $\begin{array}{c}\mathrm{T} \\
\left(\mathrm{m}^{2} \mathrm{~s}\right)\end{array}$ & $\begin{array}{l}\mathrm{k}_{\mathrm{b}} \\
\left(\mathrm{m}^{2}\right)\end{array}$ & S & $\begin{array}{c}\mathrm{U}_{\mathrm{e}} \\
\pm \log \text { units }\end{array}$ \\
\hline 1 & $P_{i}$ & 56.1 & None & 56.558 & 56.293 & 1.456 & 1.721 & 0.524 & 0.438 & 0.01 & 3.21 & $4.4 \times 10^{-7}$ & $8.6 \times 10^{-16}$ & $2.0 \times 10^{-3}$ & 1.0 \\
\hline 5 & $\mathrm{P}_{\mathrm{i}}$ & 55.7 & None & 55.956 & 55.832 & 2.058 & 2.182 & 0.328 & 0.287 & 0.1 & 3.34 & $3.3 \times 10^{-7}$ & $6.4 \times 10^{-16}$ & $1.8 \times 10^{-4}$ & $>1.0$ \\
\hline 8 & $F_{i}$ & NA & None & 57.239 & 57.608 & 0.775 & 0.406 & 0.747 & 0.867 & NA & NA & $3.6 \times 10^{-6}$ & $6.9 \times 10^{-15}$ & $1.6 \times 10^{-2}$ & 0.75 \\
\hline $9 \mathrm{~A}$ & $\mathrm{R}_{\mathrm{i}}$ & NA & None & 57.591 & 57.565 & 0.423 & 0.429 & 0.862 & 0.860 & NA & NA & $4.1 \times 10^{-5}$ & $7.9 \times 10^{-14}$ & $6.1 \times 10^{-2}$ & $>1.0$ \\
\hline $9 \mathrm{~B}$ & $\mathrm{R}_{\mathrm{i}}$ & NA & None & 57.524 & 57.476 & 0.490 & 0.538 & 0.840 & 0.824 & NA & NA & $3.9 \times 10^{-6}$ & $7.5 \times 10^{-15}$ & $1.6 \times 10^{-1}$ & $>1.0$ \\
\hline 10 & $\mathrm{P}_{\mathrm{i}}$ & 56.8 & None & 57.172 & 57.016 & 0.801 & 0.957 & 0.738 & 0.687 & 0.01 & 3.40 & $6.3 \times 10^{-7}$ & $1.2 \times 10^{-15}$ & $4.4 \times 10^{-4}$ & 1.0 \\
\hline 11 & $P_{i}$ & 56.8 & None & 57.081 & 56.976 & 0.892 & 0.997 & 0.709 & 0.674 & 0.01 & 3.20 & $1.0 \times 10^{-6}$ & $2.0 \times 10^{-15}$ & $4.4 \times 10^{-4}$ & 1.0 \\
\hline 12 & $F_{i}$ & NA & None & 57.404 & 57.723 & 0.569 & 0.250 & 0.814 & 0.918 & NA & NA & $1.4 \times 10^{-5}$ & $2.7 \times 10^{-14}$ & $1.5 \times 10^{-2}$ & 0.75 \\
\hline 13 & $\mathrm{R}_{\mathrm{i}}$ & NA & None & 57.667 & 57.587 & 0.306 & 0.386 & 0.904 & 0.874 & NA & NA & $5.8 \times 10^{-5}$ & $1.1 \times 10^{-13}$ & $6.3 \times 10^{-2}$ & 0.75 \\
\hline
\end{tabular}

Notes: $\mathrm{P}_{0}=$ initial baseline pressure assumed for start of pulse test. Corr $=$ pressure correction applied to full record following selection of $\mathrm{P}_{0}$. Unlike the data from Site 948 , data from Site 949 were not subjected to any additional corrections as there was insufficient constraint from the observations. Pressures were measured at the start and end of the time interval selected for interpretation. Vertical effective stress was measured at the pressures at the start and end of time interval selected for interpretation, based on calculations described in text and shown as pressure vs. depth trends in Figure 5A. Measured pressures are adjusted to reflect the depth at the center of the isolated interval. Modified pore pressure ratio at the measured pressures at the start and end of time interval selected for interpretation, based on calculations described in text and shown as pressure vs. depth trends in Figure $5 \mathrm{~A}$. Measured pressures are adjusted to reflect the depth at the center of the isolated interval. $\alpha=$ type curve parameter (Bredehoeft and Papadopulos, 1980) that best fits selected data; $\Delta \beta=$ shift of type curve required to best fit selected data; $\mathrm{T}=$ transmissivity; $\mathrm{k}_{\mathrm{b}}=$ bulk permeability, assuming a tested zone $70 \mathrm{~m}$ thick; $\mathrm{S}=$ storage coefficient; and $\mathrm{U}_{\mathrm{e}}=$ estimated uncertainties in transmissivity and bulk permeabilities, expressed as log units. $\mathrm{P}=$ pulse test; $\mathrm{F}=$ flow test; subscript $\mathrm{i}=$ injection; and subscript $\mathrm{w}=$ withdrawal. $\mathrm{NA}=$ not applicable. 

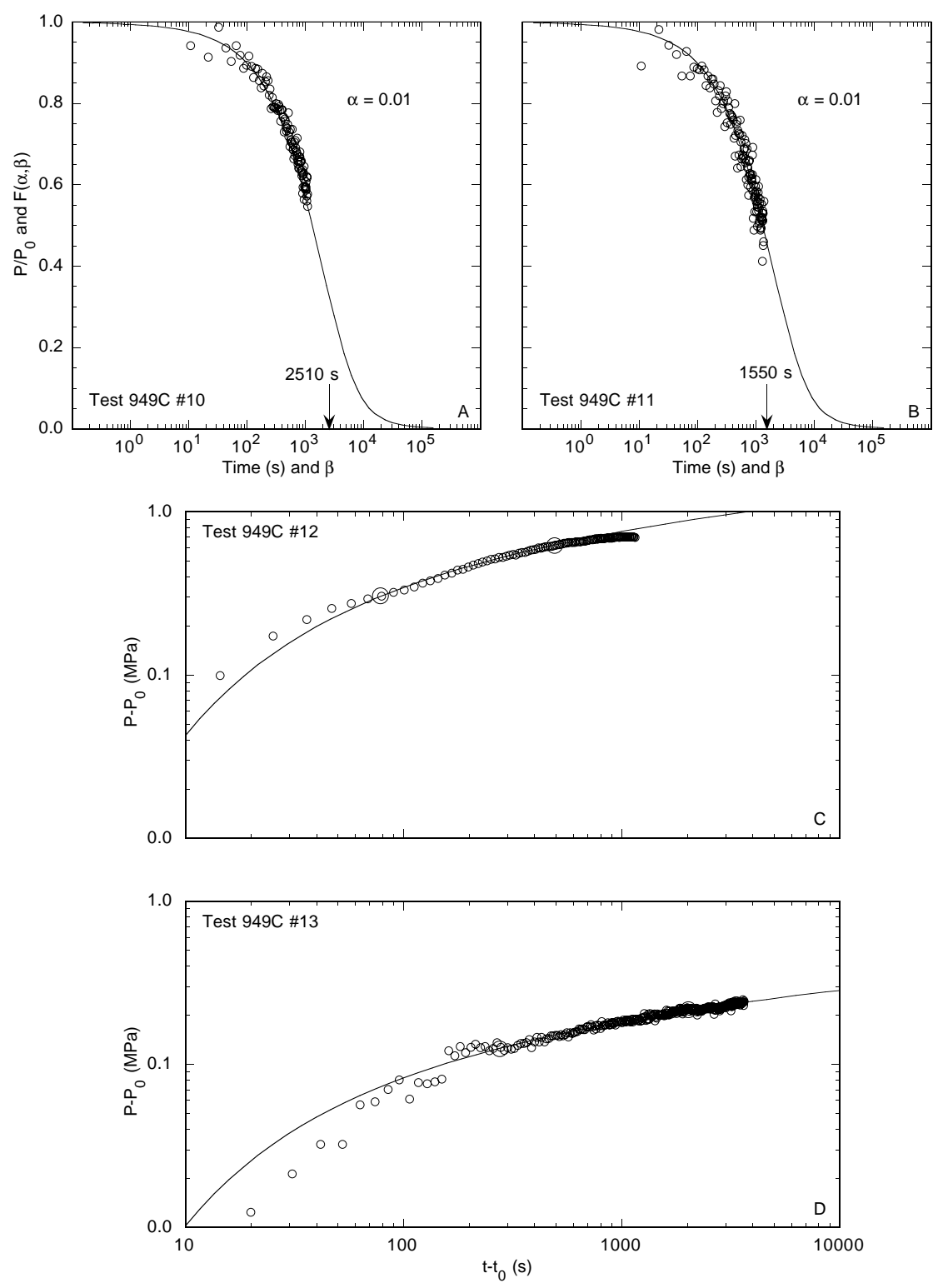

Figure 11. Analyses of test results from the second gauge deployment in Hole 949C. For the pulse tests, the arrows indicate the shift in time or $\beta$ required to obtain the illustrated fit (Bredehoeft and Papadopulos (1980). A. Normalized pressure vs. time and $\mathrm{F}(\alpha, \beta)$ vs. $\beta$ for Test 10. B. Normalized pressure vs. time and $\mathrm{F}(\alpha, \beta)$ vs. $\beta$ for Test 11. C. Pressure vs. $\log /$ time during withdrawal flow Test 12. D. Pressure vs. log/time during recovery Test 13. Large circles around data values indicate the first and last values that were used to determine the best-fitting Theis curves as shown. Recovery Test 13 was corrected for preceding flow Test 12, and then inverted so that pressures increased with time rather than decreased. The variable $t_{0}$ is the time when pumping began for flow tests, and the time when pumping stopped for recovery tests.

measurements made during the first gauge deployment in Hole 948D (Tests 1-5), and the pulse tests attempted after refilling the stand pipe during the first gauge deployment in Hole 949C (Tests 5-7). When these data are removed from consideration, the remaining data provide a more consistent trend.

The data from the three flow tests that fit the Hantush and Jacob model also fall within the trends of the Theis interpretations (Fig. 12). However, these alternative interpretations from both holes result in a narrow range of relatively high, bulk permeability values, about $2 \times$ $10^{-14}$ to $6 \times 10^{-14} \mathrm{~m}^{2}$. If properties did not change during these tests, then this range of values could reflect the bulk permeability of the tested intervals in the two holes. However, these interpretations are strongly constrained by the early-time data. These early-time data would have been the most strongly influenced by damage around the borehole, and we believe these to be less reliable that the later time data. When early-time data are neglected, the best-fitting Hantush and Jacob solutions differ little from the best-fitting Theis solutions summarized in Tables 4 and 5 .

Estimating uncertainties in the bulk permeability interpretations shown in these figures is difficult. We do not how much of the for- mation surrounding the borehole was actually tested during the experiments. We assume that lateral variations in permeability during the tests, as well as changes in properties with time, are averaged with our interpretation methods, but we do not know how these properties are actually distributed in space and time. We have attempted to estimate uncertainties by examining the range in properties that would be determined through selection of different segments of each test record. We have also examined differences in properties that would be determined from each pulse test if the initial pressure was shifted within a reasonable range $( \pm 0.1$ to $0.2 \mathrm{MPa})$. Results from pulse tests are estimated to have uncertainties no lower than \pm 1.0 log units $( \pm 1$ order of magnitude) for transmissivity and bulk permeability. Flow tests and recovery tests were assigned uncertainties of \pm 0.5 to $>1.0$ $\log$ units, based on the consistency of the pressure/time trends and the fit of the data to the Theis model.

We note that parts of the trends apparent in Figures 13 and 14 also could result from differences in measurement scale between pulse and flow tests. The pulse tests, run early in each test sequence, produced the lowest apparent bulk permeabilities; the flow tests, run later in each test sequence, produced the greatest apparent permeabili- 

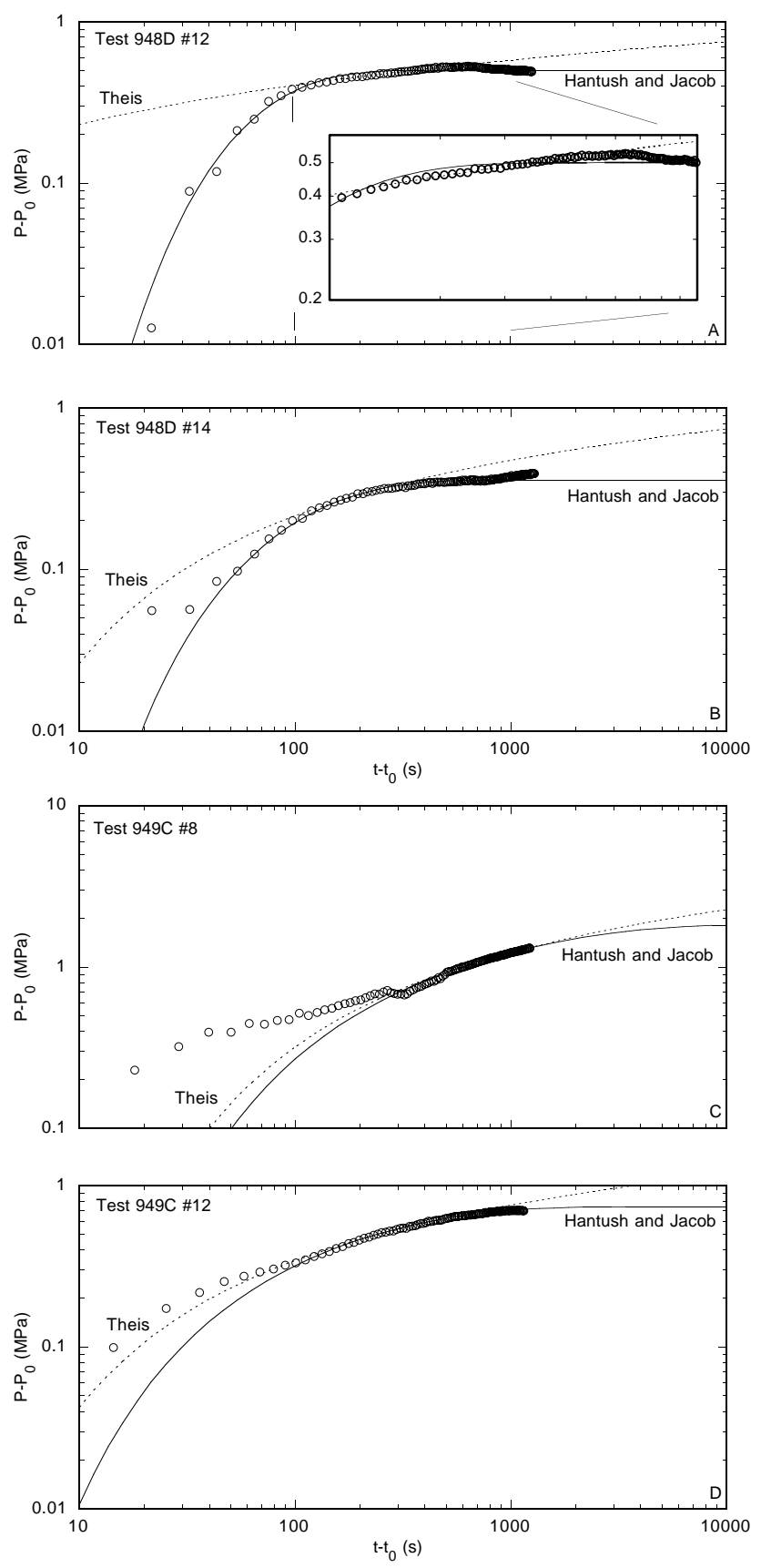

Figure 12. Analysis of flow tests conducted in Holes 948D and 949C, fit to analytic models of Theis (1935) and Hantush and Jacob (1955). Curves were fit to data segments of different lengths, with resulting transmissivity, storage, and other properties listed in Table 6 . The applicability of the different interpretations is discussed in the text. The variable $t_{0}$ is the time when pumping began. A. Hole 948D, flow test 12. B. Hole 948D, flow test 14. C. Hole 949C, flow test 8. D. Hole 949C, flow test 12 .

ties. However, even when slug tests are excluded entirely, the flow and recovery tests interpreted with the Theis model still yield an apparent bulk permeability vs. fluid pressure trend (Fig. 14).

Figure 14 illustrates the highest quality Theis model interpretations from Holes 948D and 949C. Separate plots were created for bulk permeability vs. vertical effective stress and bulk permeability vs. modified pore-pressure ratio, because of differences in sediment thickness at the sites. Least-squares best-fitting lines through the most reliable data (with equal weights applied to all tests) produce trends for the combined data sets that are very similar to those determined previously for only the Hole 948D data (Fisher et al., 1996). These results also are consistent with preliminary interpretations of additional aquifer tests conducted in Hole 949C, which was sealed with a CORK system, using the submersible Nautile in winter 1995 (Screaton et al., 1997). These latest tests were conducted at relatively high vertical effective stresses, after the fluid pressure in the borehole had stabilized to about $1 \mathrm{MPa}$ above hydrostatic (Becker et al., Chapter 19, this volume). Interpretations of these slug and flow-recovery tests fall essentially along the best-fitting lines shown in Figure 14 when these lines are extrapolated to lower fluid pressures and higher effective stresses than represented by the packer data. The new test data also lack the noise apparent in all Leg 156 data, illustrating one important advantage of making such measurements from the seafloor rather than from a moving drilling platform (Screaton et al., 1997).

\section{Implications of Packer Test Results}

The combined data set (both Holes 948D and 949C) clusters more tightly around a log/linear trend when plotted against modified porepressure ratio than when plotted against vertical effective stress (Fig. 14). This result is surprising at first because effective stress might be considered to be the more fundamental independent variable. However, if differences in this constitutive relationship reflect the different levels of structural maturity (i.e., the extent to which the sediments have been consolidated, folded, or otherwise deformed), then the modified pore-pressure plot (Fig. 14B) could provide a more consistent trend, because this independent variable combines effective stress with a proxy for such maturity: sediment thickness.

Stress conditions within the active Barbados décollement zone are unknown, although it is likely that the maximum principal stress direction is not vertical (Moore et al., 1988; Brown et al., 1994). Because of this uncertainty, it is not clear when during the testing the least principle stress was exceeded in each hole. Clearly, that stress was exceeded over some part of the tested zones, as the vertical effective stress exceeded the overburden stress at least once in both holes (Fig. 3). Based on the shape of the pressure/time curves, it appears that there was some "hydrofracturing" of the top of the isolated zone during the final flow tests in both holes. This should have led to an increase in bulk permeability as well as storativity.

Despite the differences in the absolute values of the hydrologic properties measured during testing, data from both sites follow the same general trends. When all pulse, flow, and recovery test interpretations are considered together, there appear to be order of magnitude differences in bulk permeability over a range of vertical effective stresses. The bulk permeability vs. vertical effective stress relationship defined through these in situ tests is also consistent with a variety of indirect estimates. At the upper extreme, bulk permeability approaches $2 \times 10^{-13} \mathrm{~m}^{2}$ when fluid pressure approaches lithostatic. This is approximately the same value predicted with an independent model of transient fluid flow at lithostatic pore pressure based on simple thermal considerations (Fisher and Hounslow, 1990). If most of the measured transmissivity along the décollement is concentrated within a narrow section of the fault zone, as suggested by borehole logs of bulk density (Moore et al., 1995), the bulk permeability within this thin zone could be significantly greater. At the lower extreme (projected well beyond the range of this data set), a bulk permeability of about $10^{-18} \mathrm{~m}^{2}$ is predicted when fluid pressure is hydrostatic. This lower extreme is consistent with laboratory tests of fine-grained material from the same area (Taylor and Leonard, 1990).

The Leg 156 packer data are also broadly consistent with results of packer testing at the Cascadia accretionary margin during ODP Leg 146 (Screaton et al., 1995), where bulk permeability values on 
Table 6. Summary of alternative interpretations of selected flow tests shown in Figure 12.

\begin{tabular}{|c|c|c|c|c|c|c|}
\hline Hole & Test & Method & $\underset{\left(\mathrm{m}^{2} / \mathrm{s}\right)}{\mathrm{T}}$ & $\begin{array}{c}\mathrm{k} \\
\left(\mathrm{m}^{2}\right)\end{array}$ & S & $\mathrm{r} / \mathrm{B}$ \\
\hline $948 \mathrm{D}$ & $\# 12$ & $\begin{array}{l}\text { Theis (1935) } \\
\text { Hantush and Jacob (1955) }\end{array}$ & $\begin{array}{l}4.1 \times 10^{-5} \\
2.4 \times 10^{-5}\end{array}$ & $\begin{array}{l}9.9 \times 10^{-14} \\
5.7 \times 10^{-14}\end{array}$ & $\begin{array}{l}1.2 \times 10^{-3} \\
6.6 \times 10^{-3}\end{array}$ & 0.14 \\
\hline $948 \mathrm{D}$ & $\# 14$ & $\begin{array}{l}\text { Theis (1935) } \\
\text { Hantush and Jacob (1955) }\end{array}$ & $\begin{array}{l}4.3 \times 10^{-5} \\
1.0 \times 10^{-5}\end{array}$ & $\begin{array}{l}1.0 \times 10^{-13} \\
2.5 \times 10^{-14}\end{array}$ & $\begin{array}{l}4.8 \times 10^{-2} \\
5.8 \times 10^{-2}\end{array}$ & 1.1 \\
\hline $949 \mathrm{C}$ & $\# 8$ & $\begin{array}{l}\text { Theis (1935) } \\
\text { Hantush and Jacob (1955) }\end{array}$ & $\begin{array}{l}3.6 \times 10^{-6} \\
2.9 \times 10^{-6}\end{array}$ & $\begin{array}{l}8.5 \times 10^{-15} \\
6.8 \times 10^{-15}\end{array}$ & $\begin{array}{l}1.6 \times 10^{-2} \\
1.8 \times 10^{-1}\end{array}$ & 0.23 \\
\hline $949 \mathrm{C}$ & $\# 12$ & $\begin{array}{l}\text { Theis (1935) } \\
\text { Hantush and Jacob (1955) }\end{array}$ & $\begin{array}{l}1.6 \times 10^{-5} \\
1.2 \times 10^{-5}\end{array}$ & $\begin{array}{l}3.8 \times 10^{-14} \\
2.9 \times 10^{-14}\end{array}$ & $\begin{array}{l}1.5 \times 10^{-2} \\
1.7 \times 10^{-2}\end{array}$ & 0.14 \\
\hline
\end{tabular}

Notes: $\mathrm{T}=$ transmissivity of primary aquifer, and $\mathrm{k}=$ effective bulk permeability. $\mathrm{r} / \mathrm{B}=$ dimensionless leakage parameter, and $\mathrm{r}=$ radial distance between pumping and observation wells. $B=\sqrt{\frac{T b^{\prime}}{K^{\prime}}}$, where $\mathrm{b}^{\prime}=$ thickness of confining layer, and $\mathrm{K}^{\prime}=$ vertical hydraulic conductivity of confining layer. Theis (1935) solution includes no leakage; Hantush and Jacob (1955) solution includes vertical leakage through confining layer with no storage in confining layer.
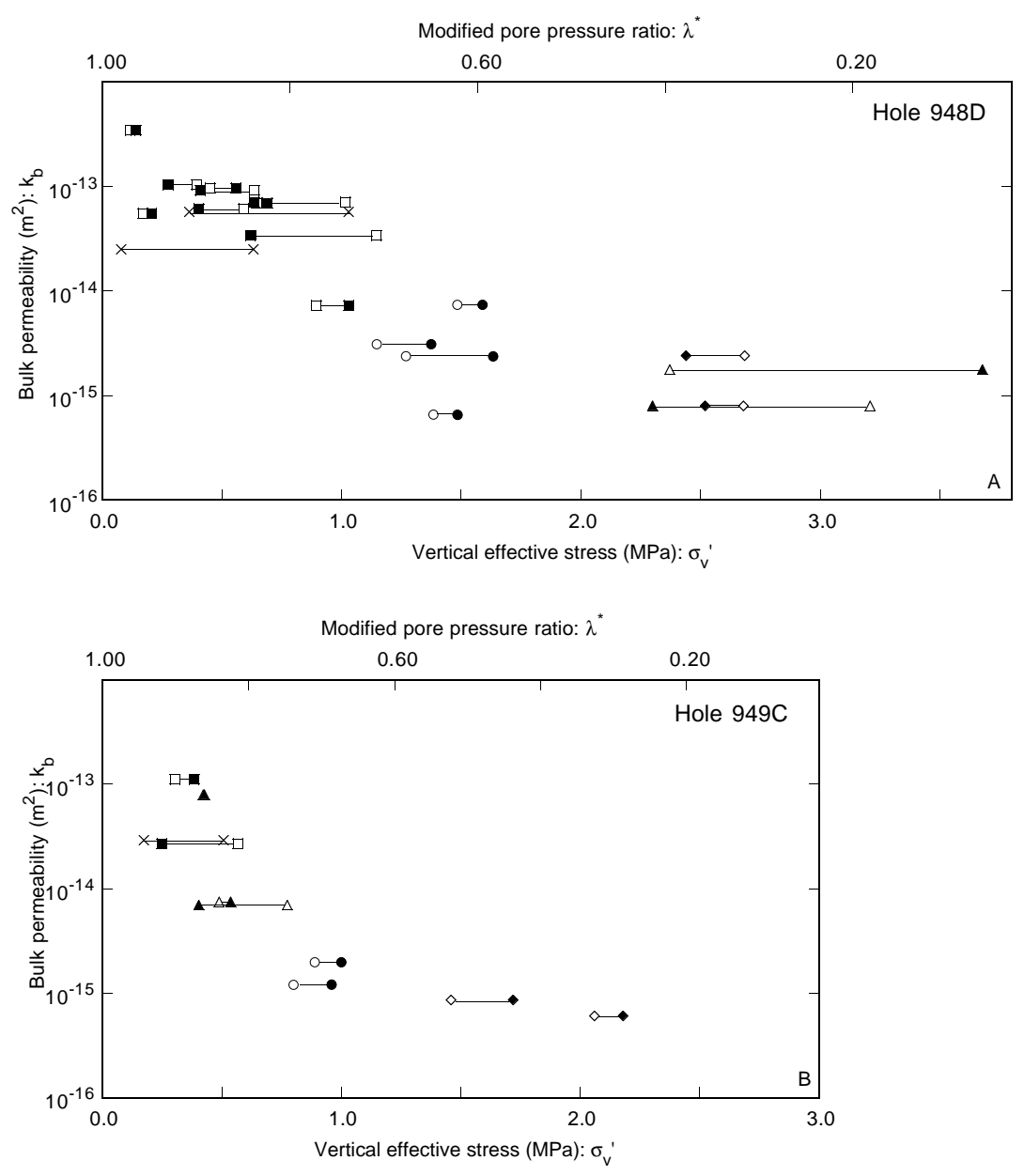

Figure 13. Bulk permeability $\left(k_{b}\right)$ vs. vertical effective stress $\left(\sigma_{v}{ }^{\prime}\right)$, and vs. modified pore-pressure ratio $(\lambda *)$ for the middle of the test intervals. Open symbols indicate the effective stresses at the start of test periods, and solid symbols indicate effective stresses at the end of test periods. Diamonds and triangles are from the first gauge deployment in each hole, circles and squares are from the second deployment in each hole. Diamonds and circles are pulse tests, triangles and squares are flow tests. Horizontal lines connect initial and final values from individual tests. The plotted data include all the values listed in Tables 4 and 5, even those with large uncertainties. $\times$ symbols indicate results of best fitting Hantush and Jacob (1955) solutions listed in Table 6 for Hole 948D Tests 12 and 14 and Hole 949C Test 12. Data from the two holes must be plotted separately in order to show $\sigma_{v}{ }^{\prime}$ and $\lambda *$ on the same plot. $\mathbf{A}$. Hole 948D. B. Hole 949C.

the order of $10^{-14}$ to $10^{-12} \mathrm{~m}^{2}$ also were determined. Screaton et al. (1995) suggest that these values, at fluid pressures close to lithostatic, reflect the development of fracture permeability along a shallow thrust fault.

The consistency of the in situ test results with other studies suggests that permeability along the décollement may vary with pore pressure along a continuum, from intergranular flow when fluid pressure is low, to "microfracture" or passage-based flow when pressure approaches lithostatic. The use of the term "fracture" in this context may actually be misleading, as it suggests the presence of competent rock. The sediments recovered from within the décollement zone during Leg 156 were soft, weak, and highly porous (Shipley, Ogawa, Blum, et al., 1995), perhaps contributing to a transition from lower permeability to higher permeability conditions as fluid pressure rose.
Prior to the collection of data presented in this report, the basis for estimating in situ permeability along an active décollement was indirect inferences drawn from laboratory measurements (Taylor and Leonard, 1990; Brown et al., 1994), numerical modeling (Screaton et al., 1990; Shi and Wang, 1988), and the apparent association of faults with flow conduits (Fisher and Hounslow, 1990; Gieskes et al., 1990). Laboratory tests of samples from the Oregon accretionary prism have defined quantitative permeability/effective stress trends (Brown, 1994; Brown et al., 1994), but matrix-scale permeability increases caused by decreases in effective stress tend to be several orders of magnitude lower than those indicated by the first in situ tests of the Barbados décollement zone. In addition, the slope of the permeability vs. effective stress curve documented by Brown et al. (1994) was lower than that reported here. These differences may re- 


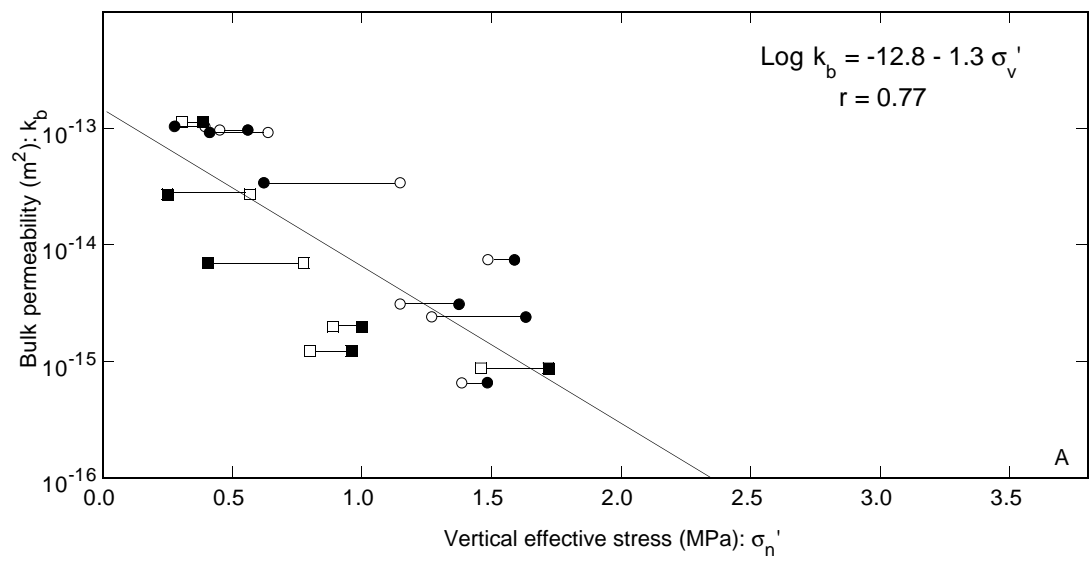

Figure 14 . A. Bulk permeability $\left(k_{b}\right)$ vs. vertical effective stress $\left(\sigma_{v}{ }^{\prime}\right)$ for both sites. B. Bulk permeability $\left(k_{b}\right)$ vs. modified pore-pressure ratio $\left(\lambda^{*}\right)$ for both sites. Open symbols indicate the effective stresses at the start of test periods, and solid symbols indicate effective stresses at the end of test periods. Circles are data from Hole 948D and squares are data from Hole 949C. Horizontal lines connect initial and final values from individual tests. Only the results of the best-fitting Theis curves, from tests having estimated uncertainties $\leq 1.0 \log$ units (Tables 4 and 5), are shown. The least-squares, bestfitting lines and their equations are shown for each figure. Data that are not included on these plots are those from the first gauge deployment in Hole 948D and from withdrawal pulse tests during the first gauge deployment in Hole 949C.

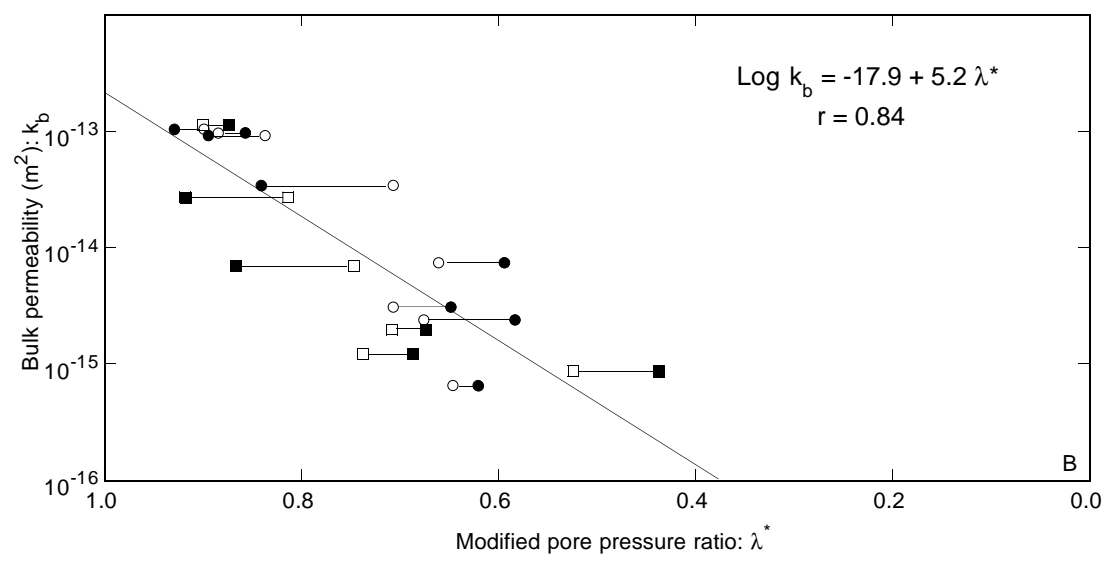

flect the corresponding scales of the experiments or the disruption of fragile sediment structures during handling and testing. Steady-state numerical models (Screaton et al., 1990) also predict permeabilities significantly lower than those measured in situ at low effective stresses, as is expected if natural prism dewatering is transient and dynamic. Higher permeabilities are predicted by transient models (Bekins et al., 1994; Henry and Wang, 1991).

The interpretation that in situ permeability may increase significantly as effective stress is reduced, even while pore pressure is significantly below lithostatic, may elucidate the discontinuous distribution along the northern Barbados décollement of zones having a negative seismic polarity, apparently an indication of elevated porosity (Shipley et al., 1994). The development of fluid pressures well above hydrostatic depends on the magnitude of fluid production relative to the in situ permeability/effective stress relationship. If the fluid production rate is too low, or if permeability changes greatly with small adjustments in fluid pressure, not enough fluid will be retained within any portion of the fault zone to allow overpressure development. Conversely, if fluid production is great enough relative to the slope of the permeability/effective stress relationship, fluid pressure can build rapidly within isolated regions until sufficient lateral permeability is generated to release the overpressured fluid.

\section{RECOMMENDATIONS FOR FUTURE TESTING}

As the results of Leg 156 packer testing are equivocal, it would be worthwhile to return to the Barbados accretionary complex and make additional measurements of in situ permeability. This was attempted during the 1995 Nautile expedition (Becker et al., Chapter 19, this volume; Screaton et al., 1997), but that program ended prematurely because of shipboard equipment failure. Another expedition may return to the Leg 156 drill sites in the next 12-18 months by submers- ible or remotely operated vehicle, to conduct flow tests of longer duration and under more carefully controlled conditions, so as to be certain that measurements are made well beyond any damaged zone around the borehole. If additional in situ laboratories are installed in the future near the Leg 156 sites, or within other accretionary systems, it will be important to do as little damage as possible to the formation while installing the well casing and screens. Although it will not be possible to avoid all formation damage, it should be possible to do less damage, particularly in comparison to that likely at Site 948.

Leg 156 operations also demonstrated that it is critical to plug the bottom of the casing string in an accretionary setting, as underconsolidated sediments at low effective stresses will flow up and into an open borehole held at hydrostatic pressure. Similarly, the wire-wrap screen used during Leg 156 clearly was an improvement over the perforated casings used during Leg 146 (Westbrook, Carson, Musgrave, et al., 1994), although it would have been desirable to emplace a true gravel- or sand-packed screen, as is often done on land. Possibilities for well development after casing and screen emplacement might also be explored, although in the absence of a sand pack, it is not clear if beneficial well development is possible.

Once the casing and screen are installed, packers should be set as soon as possible, so as to minimize the time required for formation fluid pressures to recover to their predrilling state following exposure to a hydrostatic borehole. However, it should be recognized that it may be impossible to wait, once the packer is inflated, for a complete return to predrilling conditions. This is apparent from an examination of the pressure record from the CORK experiment in Hole 949C (Becker et al., Chapter 19, this volume), which indicates that days or weeks of equilibration may be required.

Once the packer is inflated, it would be desirable to simply monitor formation pressure passively for as long as possible, perhaps for several hours. Following this baseline period, packer testing probably 
should begin with several positive pulse tests, followed by flow testing at the lowest possible flow rates. No negative pulse or flow tests should be attempted. The lowest flow rates allowed at present using the cement pumps are several liters per second, but it should be possible to temporarily install a high-pressure, low volume flow pump at the rig floor. Such a pump used for packer pulse and flow tests would allow better flow control, and would allow longer duration tests to be run without exceeding critical test pressures. Finally, post-cruise testing in sealed holes provides much quieter test data, and with the proper equipment, also could allow for longer duration tests to penetrate farther from the borehole without raising pressures in the formation above critical values.

\section{CONCLUSIONS}

The first in situ measurements along the décollement of an active accretionary complex have revealed relatively high bulk permeabilities and an apparent permeability/effective stress trend. This trend is consistent with inferences drawn from models and indirect calculations. The in situ measurements also suggest that natural fluid pressures within the décollement of the Barbados accretionary complex may be close to lithostatic, although additional analyses are required to quantitatively eliminate the drilling-induced component of excess fluid pressure. Unfortunately, the tests were of too short a duration to allow interpretation of the data with certainty, and the data from different tests are inconsistent with a single model for the formation surrounding the aquifer. Even if the data are interpreted to indicate an increase in effective permeability with fluid pressure, we cannot be certain that these properties extend beyond the damaged zone around the borehole and into the natural formation. These results remain to be confirmed through more carefully conducted experiments and modeling. Thus, the relations described herein can be considered to be a working hypotheses of the in situ hydrogeologic behavior of the Barbados décollement; only additional direct measurements will resolve the unfortunate ambiguities. Although the methodology for obtaining and interpreting these kinds of data still needs to be refined, the successes of Leg 156 indicate that the Ocean Drilling Program has made significant progress toward understanding the dynamic processes active within accretionary systems.

\section{ACKNOWLEDGMENTS}

These experiments would not have been possible without the skill, dedication, and assistance of the drilling and engineering crews of the Sedco/BP 471 (JOIDES Resolution), particularly Joe (Bubba) Attryde and Hal Holmes. The patience and support of the Leg 156 scientific party is also greatly appreciated. Funding was provided by United States Science Support Program awards to Fisher and Zwart. Detailed, patient, and thoughtful reviews were provided by $\mathrm{A}$. Moench, J. Bahr, and an anonymous reviewer.

\section{REFERENCES}

Anderson, R.N., and Zoback, M.D., 1982. Permeability, underpressures, and convection in the oceanic crust near the Costa Rica Rift, eastern equatorial Pacific. J. Geophys. Res., 87:2860-2868.

Anderson, R.N., Zoback, M.D., Hickman, S.H., and Newmark, R.L., 1985. Permeability versus depth in the upper oceanic crust: in situ measurements in DSDP Hole 504B, eastern equatorial Pacific. J. Geophys. Res., 90:3659-3669.

Becker, K., 1989. Measurements of the permeability of the sheeted dikes in Hole 504B, ODP Leg 111. In Becker, K., Sakai, H., et al., Proc. ODP, Sci. Results, 111: College Station, TX (Ocean Drilling Program), 317-325.

Becker, K., 1990a. A guide to formation testing using ODP drillstring packers. ODP Tech. Note, 14
Becker, K., 1990b. Measurements of the permeability of the upper oceanic crust at Hole 395A, ODP Leg 109. In Detrick, R., Honnorez, J., Bryan, W.B., Juteau, T., et al., Proc. ODP, Sci. Results, 106/109: College Station, TX (Ocean Drilling Program), 213-222.

Becker, K., 1991. In-situ bulk permeability of oceanic gabbros in Hole 735B, ODP Leg 118. In Von Herzen, R.P., Robinson, P.T., et al., Proc. ODP, Sci. Results, 118: College Station, TX (Ocean Drilling Program), 333-347.

Bekins, B., Blue, J.E., McCaffrey, A.M., and Dreiss, S.J., 1994. Modeling the origin of low chloride pore waters in a modern accretionary complex. Eos, 75 (supplement): 588.

Bredehoeft, J.D. and Papadopulos, S.S., 1980. A method for determining the hydraulic properties of tight formations. Water Resour. Res., 16:223-238.

Brown, K.M., 1994. Hydraulic conductivity structure of an active overpressured thrust zone. Eos, 75 (supplement): 588.

Brown, K.M., and Behrmann, J., 1990. Genesis and evolution of small-scale structures in the toe of the Barbados Ridge accretionary wedge. In Moore, J.C., Mascle, A., et al., Proc. ODP, Sci. Results, 110: College Station, TX (Ocean Drilling Program), 229-244.

Brown, K.M., Bekins, B., Clennell, B., Dewhurst, D., and Westbrook, G., 1994. Heterogeneous hydrofracture development and accretionary fault dynamics. Geology, 22:259-262.

Bylerlee, J.D., 1990. Friction, overpressure, and fault normal compression, Geophys. Res. Lett., 17:2109-2112.

Cooper, H.H., Jr., Bredehoeft, J.D., and Papadopulos, I.S., 1967. Response of a finite diameter well to an instantaneous charge of water. Water Resour. Res., 3:267-269.

Davis, D.M., 1984, The compressive mechanics of accretionary wedges applied to the Leg 78A study area near Barbados. In Biju-Duval, B., Moore, J.C., et. al., Init. Repts. DSDP, 78A: Washington (U. S. Govt. Printing Office), 699-708.

Fisher, A., Zwart, G., and the Leg 156 Scientific Party, 1996. The relation between permeability and effective stress along a plate-boundary fault, Barbados accretionary complex. Geology, 24: 307-310.

Fisher, A.T., Becker, K., and Narasimhan, T.N., 1994. Off-axis hydrothermal circulation: parametric tests of a refined model of processes at Deep Sea Drilling Project/Ocean Drilling Program Site 504. J. Geophys. Res., 99:3097-3121.

Fisher, A.T., and Hounslow, M., 1990. Transient fluid flow through the toe of the Barbados accretionary complex: evidence from ODP Leg 110 and simple analytical models, J. Geophys. Res., 95:8845-8858.

Gieskes, J.M., Vrolijk, P., and Blanc, G., 1990. Hydrogeochemistry of the northern Barbados accretionary complex transect: Ocean Drilling Program Leg 110. J. Geophys. Res., 95:8809-8818.

Haar, L., Gallagher, J.S., and Kell, G.S., 1984. NBS/NRC Steam Tables, Thermodynamic and Transport Properties and Computer Programs for Vapor And Liquid States in SI Units: Washington (Hemisphere Publ.), 263-266.

Hantush, M.S., 1960. Modification of the theory of leaky aquifers. J. Geophys. Res., 65:3713-3725.

Hantush, M.S., and Jacob, C.E., 1955. Nonsteady radial flow in an infinite leaky aquifer. Eos, 36:95-100.

Henry, P., and Wang, C.-Y., 1991. Modeling of fluid flow and pore pressure at the tow of the Barbados and Oregon accretionary wedges. J. Geophys. Res., 96:20109-20130.

Hickman, S.H., Langseth, M.G., and Svitek, J.F., 1984. In situ permeability and pore-pressure measurements near the Mid-Atlantic Ridge, Deep Sea Drilling Project Hole 395A. In Hyndman, R.D., Salisbury, M.H., et al., Init. Repts. DSDP, 78B: Washington (U.S. Govt. Printing Office), 699708.

Hubbert, M.K., and Rubey, W.W., 1959. Role of fluid pressures in mechanicas of overthrust faulting, Part 1. Mechanics of fluid-filled porous solids and its application to overthrust faulting. Geol. Soc. Am. Bull., 70:115166.

Kerr, R., 1992. Weak faults breaking out all over. Science, 255:1210-1212.

Mascle, A., Moore, J.C., et al., 1988. Proc. ODP, Init. Repts., 110: College Station, TX (Ocean Drilling Program)

Moench, A., 1985. Transient flow to a large diameter well in an aquifer with storative semiconfining layers. Water Resour. Res., 21:1121-1131.

Moore, J.C., Biju-Duval, B., Bergen, J.A., Blackington, G., Claypool, G.E., Cowan, D.S., Duennebier, F., Guerra, R.T., Hemleben, C.H.J., Hussong, D., Marlow, M.S., Natland, J.H., Pudsey, C.J., Renz, G.W., Tardy, M., Willis, M.E., Wilson, D., and Wright, A.A., 1982. Offscraping and underthrusting of sediment at the deformation front of the Barbados Ridge: Deep Sea Drilling Project Leg 78A. Geol. Soc. Am. Bull., 93:1065-1077. 
Moore, J.C., Mascle, A., Taylor, E., Andreieff, P., Alvarez, F., Barnes, R., Beck, C., Behrmann, J., Blanc, G., Brown, K., Clark, M., Dolan, J.F., Fisher, A., Gieskes, J., Hounslow, M., McLellan, P., Moran, K., Ogawa, Y., Sakai, T., Schoonmaker, J., Vrolijk, P., Wilkens, R.H., and Williams, C., 1988. Tectonics and hydrogeology of the northern Barbados Ridge: results from Ocean Drilling Program Leg 110. Geol. Soc. Am. Bull., 100:1578-1593.

Moore, J.C., Shipley, T.H., Goldberg, D., Ogawa, Y., Filice, F., Fisher, A., Jurado, M.J., Moore, G.F., Rabaute, A., Yin, H., Zwart, G., Brückmann, W., Henry, P., Ashi, J., Blum, P., Meyer, A., Housen, B., Kastner, M., Labaume, P., Laier, T., Leitch, E.C., Maltman, A.J., Peacock, S., Steiger, T.H., Tobin, H.J., Underwood, M.B., Xu, Y., and Zheng, Y., 1995. Abnormal fluid pressures and fault-zone dilation in the Barbados accretionary prism; evidence from logging while drilling. Geology, 23:605-608.

Neuzil, C.E., 1982. On conducting the modified "slug" test in tight formations. Water Resour. Res., 18:439-441.

Papadopulos, I.S., and Cooper, H.H., Jr., 1967. Drawdown of a well of large diameter. Water Resour. Res., 3: 241-244.

Rice, J., 1992. Fault stress, pore pressure distributions, and the weakness of the San Andreas Fault. In Evans, B., and Wong, T.-F. (Eds.), Fault mechanics and transport properties of rocks: London (Academic Press), 475-504.

Screaton, E.J., Carson, B., and Lennon, G.P., 1995. In situ permeability tests at Site 892: characteristics of a hydrogeologically active fault zone on the Oregon accretionary prism. In Carson, B., Westbrook, G.K., Musgrave, R.J., and Suess, E. (Eds.), Proc. ODP, Sci. Results, 146 (Pt 1): College Station, TX (Ocean Drilling Program), 291-297.

Screaton, E.J., Fisher, A.T., Carson, B., Becker, K., 1997. Barbados Ridge hydrogeologic tests: implications for fluid migration along an arctic décollement. Geology, 25:239-242.

Screaton, E.J., Wuthrich, D.R., and Dreiss, S.J., 1990. Permeabilities, fluid pressures, and flow rates in the Barbados Ridge Complex. J. Geophys. Res., 95:8997-9007.

Shi, Y., and Wang, C.-Y., 1988. Generation of high pore pressures in accretionary prisms: inferences from the Barbados Subduction Complex. J. Geophys. Res., 93:8893-8909.

Shipboard Scientific Party, 1988a. Site 671. In Mascle, A., Moore, J.C., et al., Proc. ODP, Init. Repts., (Pt. A), 110: College Station, TX (Ocean Drilling Program), 67-204. 1988b. Site 675. In Mascle, A., Moore, J.C., et al., Proc. ODP, Init. Repts., (Pt. A), 110: College Station, TX (Ocean Drilling Program), 487-507.

1995a. Site 948. In Shipley, T.H., Ogawa, Y., Blum, P., et al., Proc. ODP, Init. Repts., 156: College Station, TX (Ocean Drilling Program), 87-192.

1995b. Site 949. In Shipley, T.H., Ogawa, Y., Blum, P., et al., Proc. ODP, Init. Repts., 156: College Station, TX (Ocean Drilling Program), 193-257.

Shipley, T.H., Moore, G.F., Bangs, N.L., Moore, J.C., and Stoffa, P.L., 1994. Seismically inferred dilatancy distribution, northern Barbados Ridge décollement: implications for fluid migration and fault strength. Geology, 22:411-414.

Shipley, T.H., Ogawa, Y., Blum, P., et al., 1995. Proc. ODP, Init. Repts., 156: College Station, TX (Ocean Drilling Program).

Stommel, H., 1965. The Gulf Stream: Berkeley, CA (University of California Press).

Taira, A., Hill, I., Firth, J.V., et al., 1991. Proc. ODP, Init. Repts., 131: College Station, TX (Ocean Drilling Program).

Taylor, E., and Leonard, J., 1990. Sediment consolidation and permeability at the Barbados forearc. In Moore, J.C., Mascle, A., et al., Proc. ODP, Sci. Results, 110: College Station, TX (Ocean Drilling Program), 289-308.

Theis, C.V., 1935. The lowering of the piezometer surface and the rate and discharge of a well using ground-water storage, Trans. Am. Geophys. Union, 16:519-524.

von Huene, R., and Lee, H.J., 1983. The possible significance of pore fluid pressures in subduction zones. In Watkins, J.S., and Drake, C.L. (Eds.), Studies in Continental Margin Geology. AAPG Mem., 34:781-789.

Westbrook, G.K., Carson, B., Musgrave, R.J., et al., 1994. Proc. ODP, Init. Repts., 146 (Pt 1): College Station, TX (Ocean Drilling Program).

Date of initial receipt: 1 February 1996

Date of acceptance: 27 August 1996

Ms 156SR-027 